\title{
Microearthquake Study of the Salton Sea Geothermal Field, California: Evidence of Stress Triggering
}

Austin A. Holland

February 2002

Idaho National Engineering and Environmental Laboratory Bechtel BWXT Idaho, LLC 
INEEL/EXT -02-00191

\title{
Microearthquake Study of the Salton Sea Geothermal Field, California: Evidence of Stress Triggering
}

\author{
Austin A. Holland \\ February 2002 \\ Idaho National Engineering and Environmental Laboratory \\ Geosciences Department \\ Idaho Falls, Idaho 83415 \\ Prepared for the \\ U.S. Department of Energy \\ Assistant Secretary for Environmental Management \\ Under DOE Idaho Operations Office \\ Contract DE-AC07-99ID13727
}




\title{
MICROEARTHQUAKE STUDY OF THE SALTON SEA GEOTHERMAL FIELD, CALIFORNIA: EVIDENCE OF STRESS TRIGGERING
}

by

Austin Adams Holland, B.S.

\author{
THESIS \\ Presented to the Faculty of the Graduate School of \\ The University of Texas at El Paso \\ in Partial Fulfillment \\ of the Requirements \\ for the Degree of
}

MASTERS OF SCIENCE

Geological Sciences

THE UNIVERSITY OF TEXAS AT EL PASO

May 2002 


\section{ACKNOWLEDGEMENTS}

I would like to thank the Department of Energy and the Idaho National Engineering and Environmental Laboratory (INEEL; Bechtel BWXT Idaho, LLC contract no. DE-AC07-99ID13727) for funding most of the work done in this thesis under the Laboratory Directed Research and Development funding through the Renewable Energy and Resources program. I would also like to thank the INEEL degree program for facilitating completion of my degree while working. I would like to thank Dr. Diane Doser for her many hours of review and helpful suggestions. I would also like to thank Suzette Payne and Richard Smith with the INEEL for their help and support through this process.

December 18, 2001 


\begin{abstract}
A digital network of 24 seismograph stations was operated from September 15, 1987 to September 30, 1988, by Lawrence Livermore National Labs and Unocal as part of the Salton Sea Scientific Drilling Project to study seismicity related to tectonics and geothermal activity near the drilling site. More than 200 microearthquakes were relocated in this study in order to image any pervasive structures that may exist within the Salton Sea geothermal field. First, detailed velocity models were obtained through standard 1-D inversion techniques. These velocity models were then used to relocate events using both single event methods and Double-Differencing, a joint hypocenter location method. An anisotropic velocity model was built from anisotropy estimates obtained from well logs within the study area. During the study period, the Superstition Hills sequence occurred with two moderate earthquakes of MS 6.2 and MS 6.6. These moderate earthquakes caused a rotation of the stress field as observed from the inversion of first motion data from microearthquakes at the Salton Sea geothermal field. Coulomb failure analysis also indicates that microearthquakes occurring after the Superstition Hills sequence are located within a region of stress increase suggesting stress triggering caused by the moderate earthquakes.
\end{abstract}




\section{TABLE OF CONTENTS}

Page

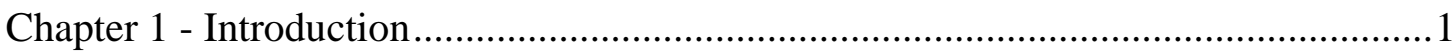

Chapter 2 - Geological and Geophysical Background ......................................... 4

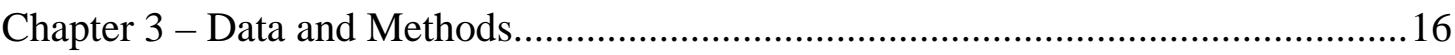

Section 3.1 Microearthquake Survey ........................................................... 16

Section 3.2 Hypoinverse ............................................................................ 19

Section 3.3 Inversion for $1-\mathrm{D}$ velocity model...............................................20

Section 3.4 Estimation of anisotropy from well logs.......................................2

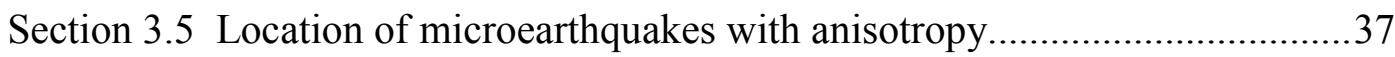

Section 3.6 Location of microearthquakes using HypoDD ..............................41

Section 3.7 Focal mechanisms and Coulomb failure analysis ..........................46

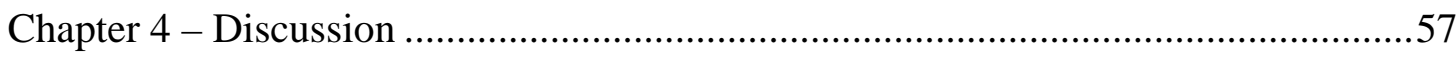

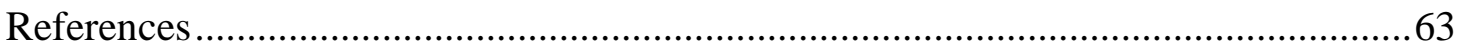

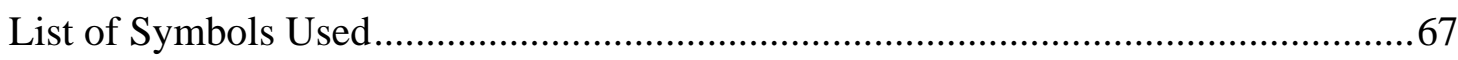

Appendix A - Description of Well Logs from the Salton Sea Geothermal

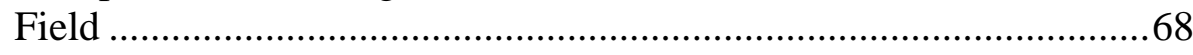

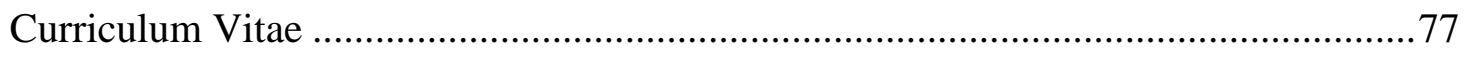




\section{LIST OF TABLES}

Page

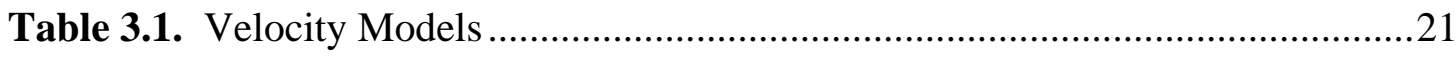

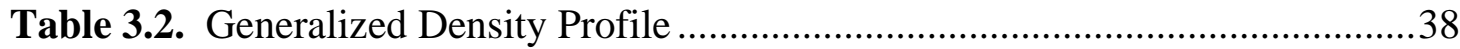

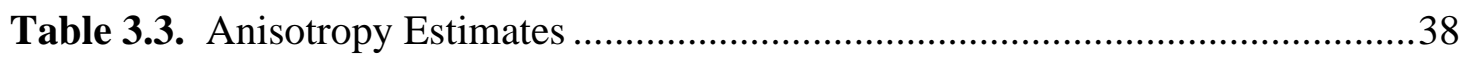

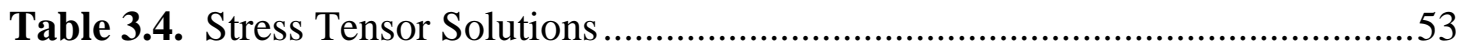

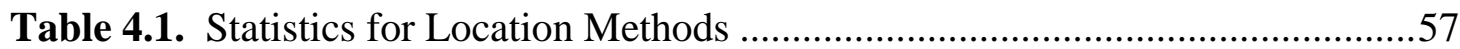




\section{LIST OF FIGURES}

Page

Figure 2.1. Location Map (Salton Trough) ........................................................5

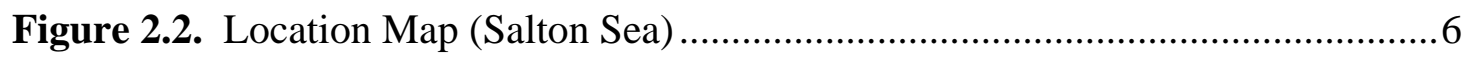

Figure 2.3. Interpreted Refraction Lines .......................................................

Figure 2.4. Reference Map Superstition Hills Sequence .....................................13

Figure 3.1. Station Location Map .................................................................... 17

Figure 3.2. Waveform Distribution for Earthquakes ........................................ 18

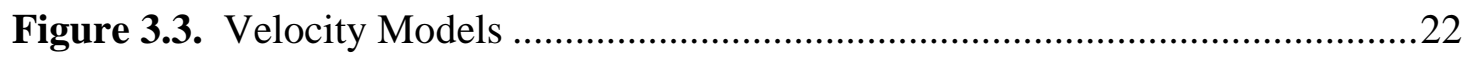

Figure 3.4. VELEST P-wave Station Delays ................................................. 24

Figure 3.5. VELEST S-wave Station Delays ....................................................25

Figure 3.6. VELEST Hypocenter Locations and Ray Coverage .............................26

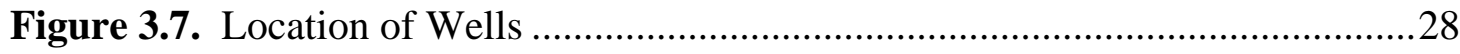

Figure 3.8. Correlation Functions (Hudson Ranch Unit 1)....................................30

Figure 3.9. Transit Time verses Deep Induction (California State 2-14) ..................31

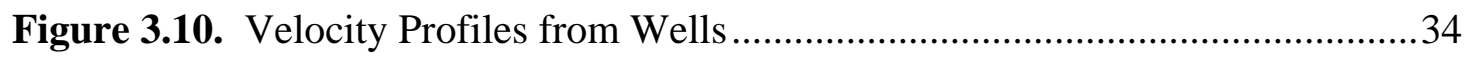

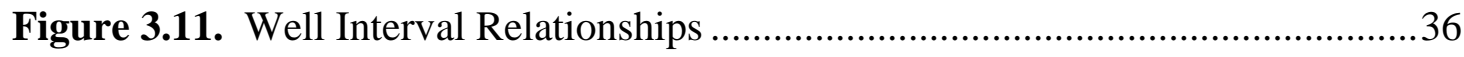

Figure 3.12. EQLOC2 Epicenter Locations .................................................. 39

Figure 3.13. EQLOC2 Cross Sections .......................................................... 40

Figure 3.14. Hypoinverse Epicenter Locations............................................43 
Figure 3.15. Hypoinverse Cross Sections .........................................................44

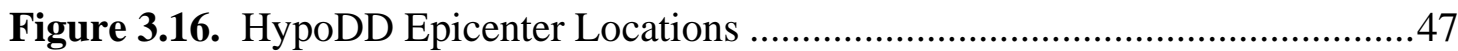

Figure 3.17. HypoDD Cross Sections ......................................................... 48

Figure 3.18. Epicenter Locations Distribution in Relation to Superstition Hills

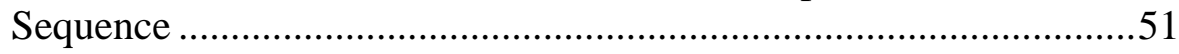

Figure 3.19. Cross Sections Distribution in Relation to Superstition Hills Sequence .......................................................................52

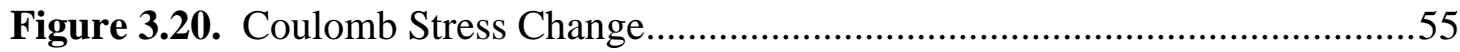




\section{CHAPTER 1}

\section{Introduction}

Microearthquake studies at geothermal fields can provide insight, at a reasonable cost, into the interconnectedness of fracture systems that control fluid migration in geothermal fields. The Department of Energy (DOE) currently has an initiative to increase the amount of geothermal production within the western United States. This initiative is in response to rising energy costs and a decrease in oil reserves making geothermal energy more attractive in the future. As part of this initiative the DOE states that one research need is the ability to image deep fracture systems within geothermal fields. Microearthquake surveys such as the one conducted at the Salton Sea geothermal field (SSGF) in southern California, may provide a useful tool in imaging these deep structures.

The Salton Sea geothermal field is one of several geothermal fields in the Imperial Valley, southern California, and the Mexicali Valley, Mexico. These valleys are also active tectonic features that exhibit high rates of seismicity. The SSGF is a waterdominated field located in proximity to active strike-slip faults and a diffuse zone of seismicity. Accurate microearthquake locations could help to image deep large scale fracture systems in such a geothermal field. 
A digital network of 24 seismograph stations was operated from September 15, 1987 to September 30, 1988 at the SSGF, California, as part of the Salton Sea Scientific Drilling Project. This network was operated by Lawrence Livermore National Lab (LLNL) and Unocal. LLNL operated 17 three-component seismographs, which had a high signal to noise ratio and recorded almost 700 earthquakes during the study period. The seven vertical component stations, operated by Unocal, together with LLNL seismic recorders collected more than 200 earthquakes. The seven stations operated by Unocal were part of a permanent network required by the state of California. This data set is one of the few to have been released by industry in the United States. The geothermal industry has not given out many data sets in order to avoid any causal relationships to be established between production activity and induced seismicity.

In order to better image fracture systems within the SSGF, several location methods were applied to the microearthquakes. First, hypocenter locations were improved by developing isotropic and anisotropic detailed 1-D velocity models for the study area. Geothermal fields often have significant velocity anisotropy as seen by Romero et. al. (1994). Accounting for this anisotropy may provide another means to obtain accurate hypocenter locations. Anisotropy of the geothermal field was assessed using available well logs within the study area. Isotropic velocity models were developed using standard inversion techniques

Both single event and joint hypocenter techniques were used with these velocity models to locate earthquakes within the SSGF. Single event techniques can provide highly accurate locations in small study areas such as this one, but may not accurately 
depict the interrelatedness of earthquakes. Joint hypocenter techniques are good at determining highly accurate relative locations between earthquakes, but often sacrifice high quality locations to obtain the best average locations. Both techniques can provide insight into the true nature of observed seismicity.

The proximity of the Salton Sea geothermal field to active strike-slip faults in southern California may also provide insight into the controls an active tectonic region may impose on a geothermal system. During the microearthquake recording period two moderate earthquakes (Ms 6.2 and Ms 6.6) occurred in proximity to the SSGF. These earthquakes allowed the examination of how seismicity at a geothermal field responds to stress changes associated with large earthquakes through inversion of first motion data for stress field orientations within the SSGF, before and after the moderate earthquakes. Changes in Coulomb failure stress due to the moderate earthquakes were compared to locations of microearthquakes to see if conditions within the SSGF were favorable for stress triggering. 


\section{CHAPTER 2}

\section{Geological and Geophysical Background}

The Salton Sea geothermal field is located at the southern end of the Salton Sea, California (Figure 2.1). This area is located in the northern part of Salton Trough; a large nearly-linear feature extending from the Gulf of California to the northern end of the Salton Sea. This topographic depression was formed by extension associated with the East Pacific Rise and the opening of the Gulf of California (Sharp, 1982). The northern end of this extensional trough is called the Imperial Valley. The Imperial Valley has had many large historic earthquakes. There are also a good number of geothermal fields located within the Imperial Valley and the Salton Trough. Extension in the Imperial Valley is thought to occur as leaky transform faulting and accommodation strike-slip (Johnson and Hadley, 1976). The Imperial Valley has subsided through extension to accommodate about $6 \mathrm{~km}$ of sediment (Sharp, 1982).

The right-lateral San Andreas Fault system (Figure 2.2) can be traced at the surface as far as $20 \mathrm{~km}$ north of the Salton Sea geothermal field. The San Andreas may continue in the subsurface further south beneath the Salton Sea toward the geothermal field (Sharp, 1982). The Imperial Valley fault runs parallel to the axis of the Imperial Valley. Its northern terminus lies just south of the Salton Sea. Therefore the Salton Sea geothermal field lies at an 


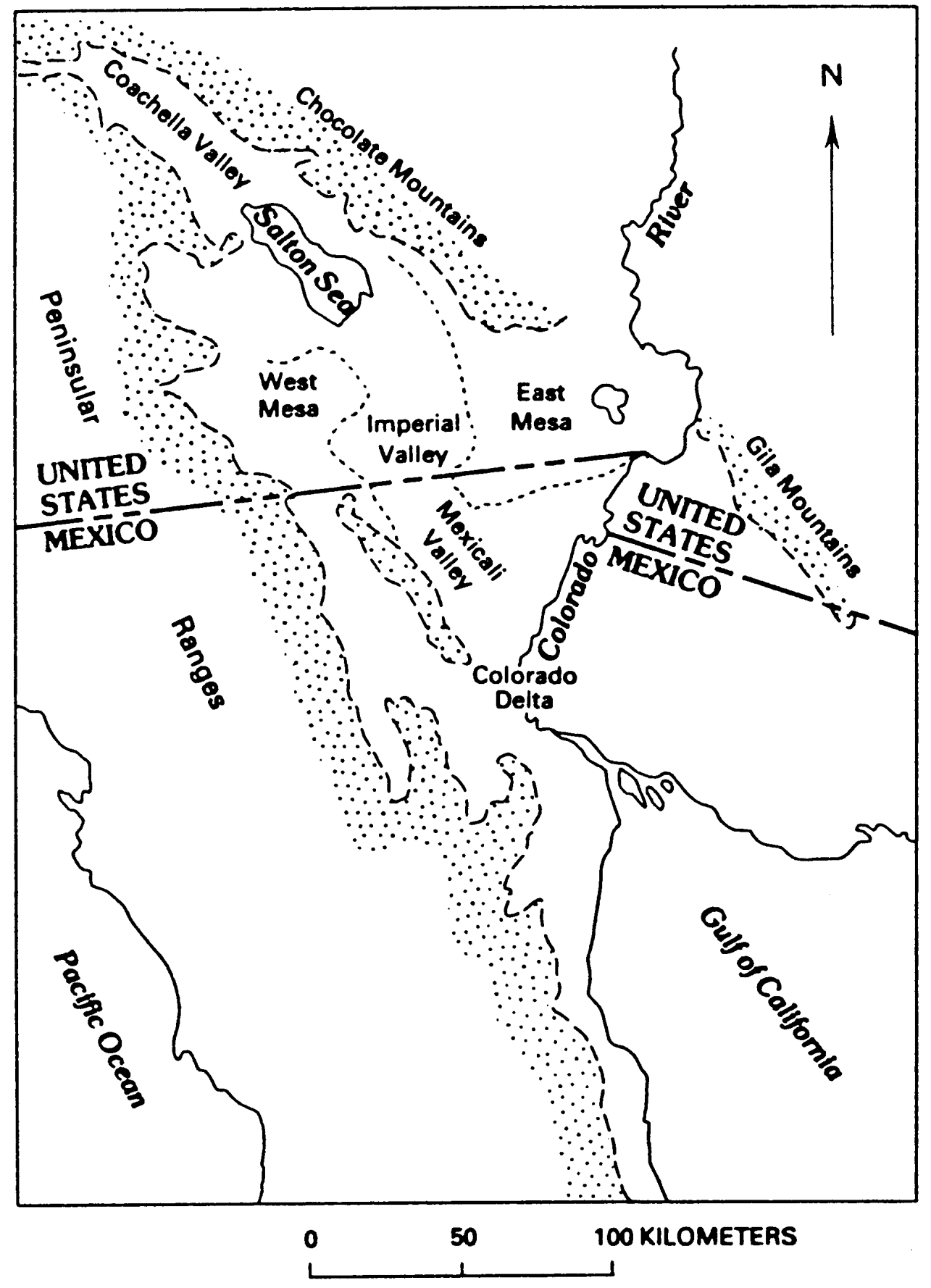

Figure 2.1. Location map of Salton trough which lies between crystalline ranges shown (stippled) from Sharp (1982). 


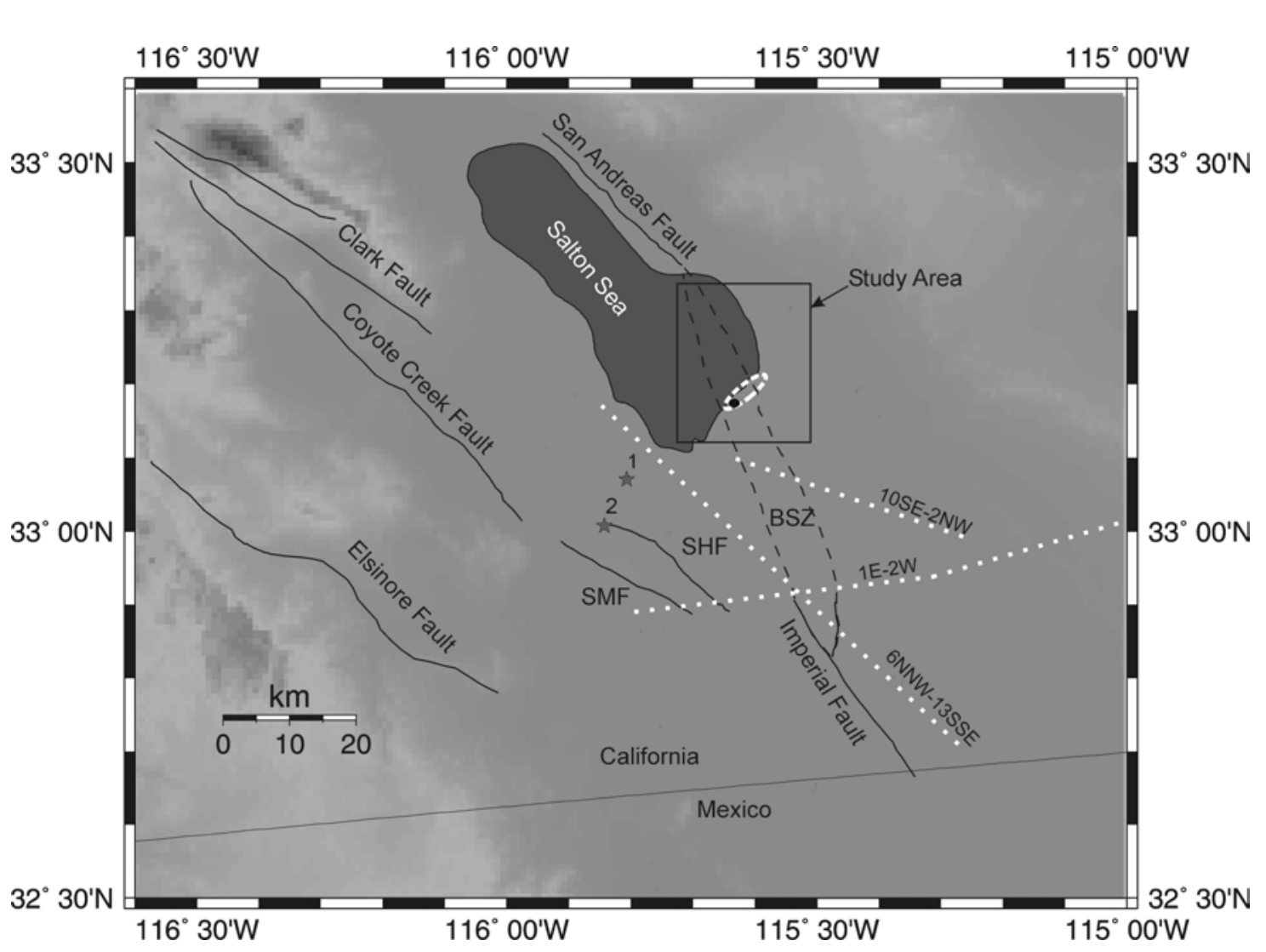

Figure 2.2. Location map for areas around Salton Sea. Faults are shown as continuous lines; Superstition Hills (SHF), Superstition Mountain (SMF), Brawley Seismic Zone (BSZ; dashed region). 1987 Superstition Hills main events are shown as stars. General location of geothermal field shown as white-bordered region. Location of Obsidian Buttes shown as dark circle. Dotted white lines indicate refraction lines of Fuis et. al. (1982) near geothermal field. 
interesting place, tectonically. It is within the transition from the San Andreas transform boundary to the divergent plate boundary of the East Pacific Rise

The geology within the Imperial Valley is dominated by a large accumulation of sediments and recent volcanics. The sediment was deposited from the Miocene to midPleistocene from the ancient Colorado River. In the late Pleistocene the Salton Sea became isolated from the Gulf of California by build-up of deltaic alluvium from the Colorado River (Sharp, 1982). Since the Salton Sea was cut off from the gulf, sedimentation has been restricted to inland seas, deltas, and alluvial fans from the nearby regions of high topography which bound the valley (Sharp, 1982). The present day Salton Sea formed by flooding from the Colorado River due to inadvertent diversion of the river into a canal early in the 1900's (Lofgren, 1978). Current measurements of crustal movement suggest as much as $4 \mathrm{~cm}$ per year of downwarping occurs due to loading and tectonics (Lofgren, 1978). The west side of the basin is bounded by Cretaceous granites of the southern California Batholith and pre-batholithic metasedimentary and meta-volcanics. The east side of the basin is bounded by Pre-Cambrian crystalline rocks and Mesozoic granites (Sharp, 1982).

The Salton Sea geothermal field is a water dominated highly saline system. Its primary heat source is derived from several rhyolitic domes, Obsidian Buttes, which were extruded in the Quaternary (Younker et. al., 1982; Helgeson, 1968). Within the geothermal field is a great volume of volcanic rock to provide heat to the system. Bimodal tholeitic basalts characteristic of extensional tectonics lie within the geothermal field at depths as shallow as one to two kilometers as observed in geothermal wells. 
These basalts are similar to those seen in the Gulf of California (Younker et. al., 1982). A Bouguer gravity high exists within the area of high heat flow in the geothermal field (Younker et. al., 1982). This gravity anomaly has been attributed to significant crustal thinning. Aeromagnetic data show a high magnetic anomaly within the region of high heat flow, most likely due to a significant intrusives volume of at depths greater than two kilometers (Younker et. al., 1982). Newark et. al. (1988) define a broad region of high conductive heat flow around the Salton Sea geothermal field covering more than a 300 $\mathrm{km}^{2}$ area with temperature gradients of about $0.1^{\circ} \mathrm{C} / \mathrm{m}$. Three localized anomalies exist within the region of high heat flow with near surface gradients ranging from $0.4^{\circ} \mathrm{C} / \mathrm{m}$ to $0.8^{\circ} \mathrm{C} / \mathrm{m}$. The highest gradients may be very limited in vertical extent, occurring over a depth on the order of a few hundred meters (Newark et. al., 1988).

Fuis et. al. (1982) modeled a mafic sub-basement with velocities of $7.2 \mathrm{~km} / \mathrm{s}$ at depths of $14 \mathrm{~km}$ based on seismic refraction data. The location of the refraction lines and their interpretation can be seen in Figures 2.2 and 2.3, respectively. Overlying the mafic sub-basement is a transition zone containing sheeted dikes and sills with velocities ranging from 6.6 to $6.8 \mathrm{~km} / \mathrm{s}$ (Fuis et. al., 1982). Altered basaltic dikes are also encountered at shallow depths within wells in the geothermal field (Younker et. al., 1982). Magnetic data also suggest intrusives at depth (Younker et. al., 1982).

Temperatures at $2 \mathrm{~km}$ depth within the field are $200{ }^{\circ} \mathrm{C}$ higher than nongeothermal areas of the Imperial Valley (Younker et. al., 1982). The velocity depth curves observed for the area are consistent with the closing of cracks and porosity associated with diagenesis, with the green-schist facies beginning at about $5 \mathrm{~km}$ depth 


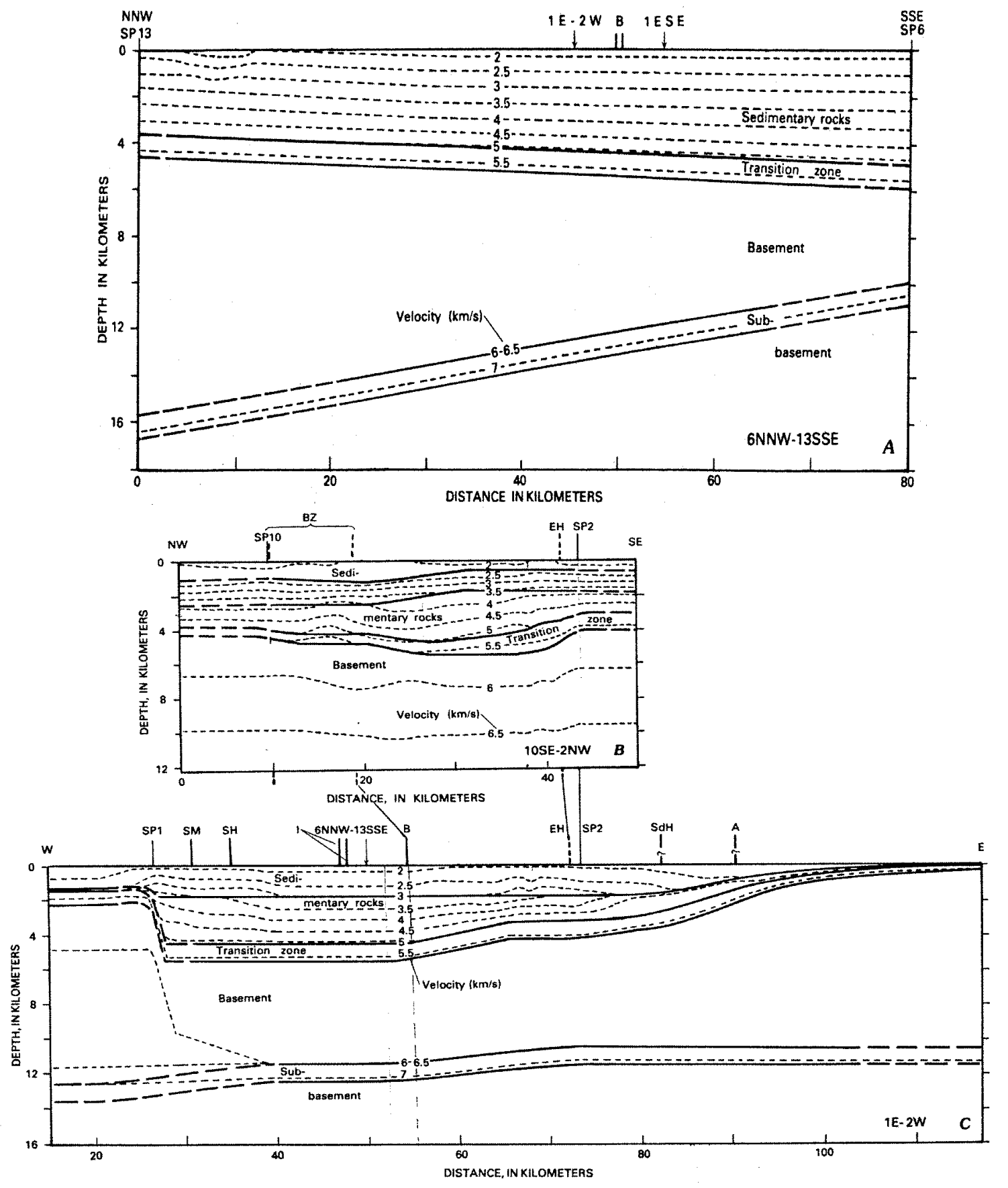

Figure 2.3. Interpretation of refraction lines from Fuis et. al. (1982) corresponding to lines shown in Figure 2.2. A) top; line 6NNW-13SSE which extends from southwestern Salton Sea to the Mexico border, B) middle, line 10SE-2NW crosses the middle portion of the BSZ; C) bottom, line 1E-2W strikes across the BSZ and the southern end of SHF and SMF. 
(Fuis et. al., 1982). Fuis et. al. (1982) explain their lack of observed reflections from the sediment-basement interface as caused by the increasing metamorphism of sediments with depth.

Younker et. al. (1982) break the geothermal field into three units: the cap rock, upper reservoir rock, and hydrothermally altered reservoir rock. The cap rock extends from the surface to $700 \mathrm{~m}$ depth in the north and to $250 \mathrm{~m}$ depth in the south. The cap rock contains unconsolidated clay, silt, and gravel with anhydrites and a carbonate matrix that increases in volume towards the base of the cap rock. This unit has high thermal gradients. The upper reservoir rocks are indurated sandstones, siltstones, and shales. These rocks show secondary alteration which do not dramatically alter the physical properties of the rock. The thickness of this unit increases from east to west. The porosity is maintained within the upper reservoir rock by faulting and hydraulic fracturing. The hydrothermally altered reservoir rocks show reduced porosity and permeability due to mineralization of epidote and silica. Flow within the SSGF has been modeled with large-scale horizontal transport from the area of Obsidian Buttes (Figure 2.2) towards the margins of the field, overprinted by small-scale vertical convection (Younker et. al., 1982).

In 1986 a deep research borehole, California State 2-14, reached a depth of 3.22 $\mathrm{km}$ at the Salton Sea Geothermal Field for the Salton Sea Scientific Drilling Project. This well is described by Elders and Sass (1988) and provides a significant context for analysis in this study. The primary lithologies encountered in State 2-14 are lacustrine shales and siltstones as well as bedded anhydrites. Sandstones were deposited as 
lacustrine deltaic deposits and channel meander fill. These sedimentary rocks range from Pliocene to Pleistocene in age (Herzig and Mehegan, 1988). State 2-14 encountered a silicic tuff and two sills of altered diabase. The altered diabase sills are most likely hypabyssal intrusions associated with the rhyolite domes found within the geothermal field. The diabase sills are partly altered to the greenschist facies suggesting hydrothermal alteration after emplacement (Herzig and Elders, 1988). State 2-14 also provided additional heat flow data for the Salton Sea Geothermal Field. Sass et. al. (1988) found heat flow values at shallow depths ranging from about $350 \mathrm{~mW} / \mathrm{m}^{2}$ to as much as $450 \mathrm{~mW} / \mathrm{m}^{2}$.

The Imperial Valley has several major fault zones on which the majority of earthquake activity occurs (Figure 2.2). Most notably, the known southern extent of the San Andreas fault ends just north of the study area on the northeast side of the Salton Sea (Sharp, 1982). The southernmost segment of the San Andreas shows evidence of Holocene faulting; however, current seismicity is quite low (Sharp, 1982). The Imperial Valley Fault has a recurrence time for damaging earthquakes of about 11 years (Johnson and Hill, 1982). The Brawley Seismic Zone is a zone defined by a dense north-south lineament of seismicity roughly linking the Imperial Fault to the San Andreas Fault (Johnson and Hill, 1982). The maximum depth of earthquakes within this zone is $8 \mathrm{~km}$, with most occurring near $5 \mathrm{~km}$ depth. The Brawley Seismic Zone passes through the Salton Sea geothermal field. The San Jacinto Fault Zone enters the Salton Trough from the northwest and splays into many segments including the Clark, Coyote Creek, Superstition Hills and Superstition Mountain faults (Sharp, 1982). 
The Superstition Hills Fault ruptured during the study period on November 24, 1987. The Superstition Hills sequence consisted of seven foreshocks and two main events, Ms 6.2 and Ms 6.6, separated by about 12 hours (Magistrale et. al., 1989). The location of the two main events within the Superstition Hills sequence can be seen in Figure 2.2. The foreshocks, the first main event, and its aftershocks demarcate the northeast trending Elmore Ranch cross-fault structure that extends from the Superstition Hills fault towards the southern end of the Brawley Seismic Zone (Magistrale et. al., 1989). This trend is shown in Figure 2.4. These events generally show left-lateral strikeslip focal mechanisms (Magistrale et. al., 1989).

The second main shock and its aftershocks occurred to the west of the observed surface rupture shown in Figure 2.4. The second mainshock was quite shallow $(1.9 \mathrm{~km})$ and appeared to contain multiple sources (Magistrale et. al., 1989). The second event shows a northwest striking right-lateral strike-slip mechanism consistent with the observed aftershocks and surface rupture (Magistrale et. al., 1989). Hudnut et. al. (1989) explained the Superstition Hills Sequence as cross-fault triggering on a conjugate fault system. Rupture of the Elmore Ranch fault reduced normal stress and triggered rupture on the Superstition Hills fault after a delay. The delay between the two largest earthquakes is attributed to fluid diffusion. Magistrale et. al. (1989) found that two velocity models were necessary for location of this sequence, indicating significant velocity heterogeneity, which can be attributed to a basin-bounding fault that juxtaposes crystalline basement against sedimentary units. Since these events occurred 


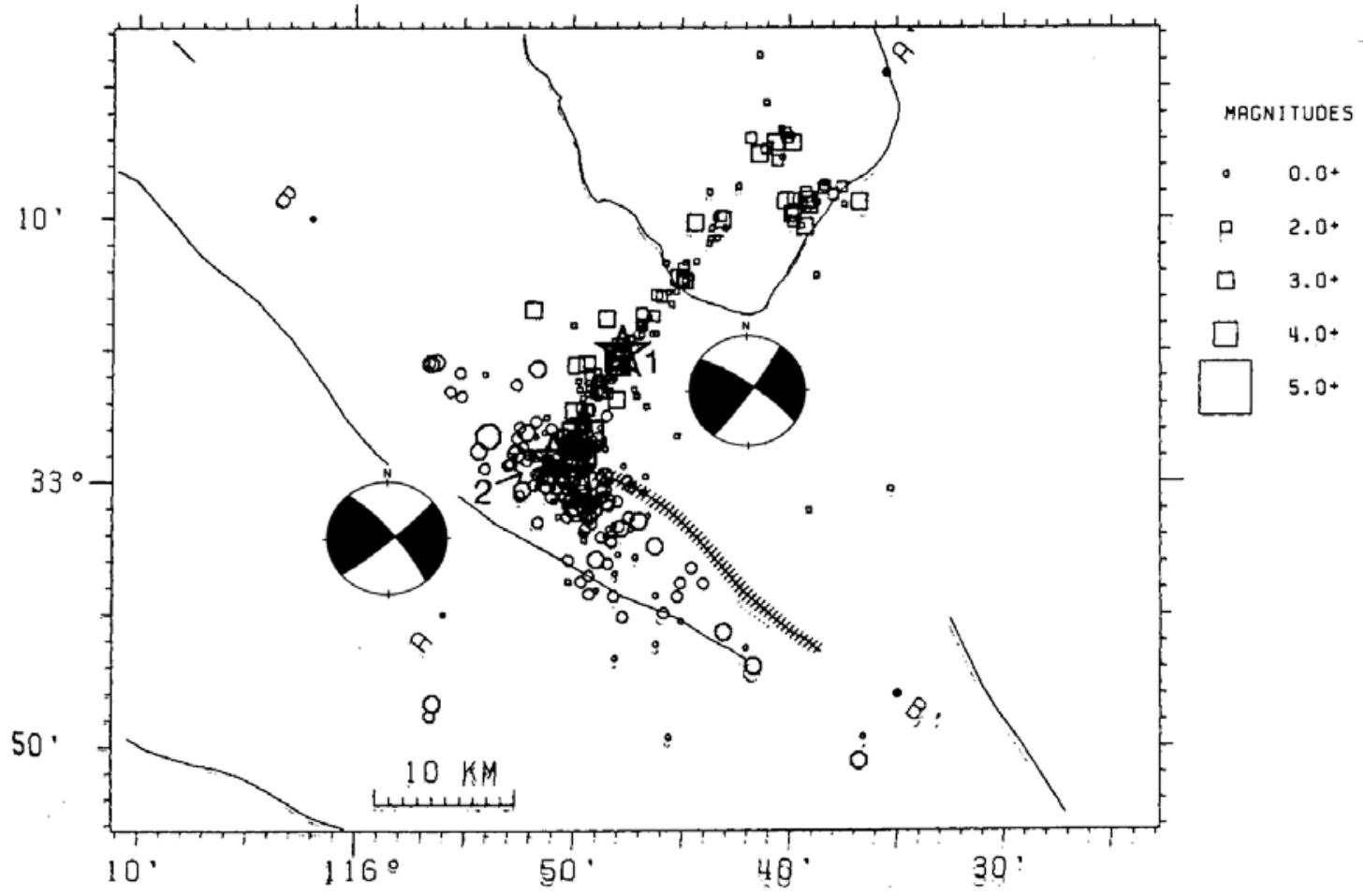

Figure 2.4. Reference map for Superstition Hills sequence with first and second main events labeled and marked with stars. Events occurring before event 2 are shown by squares. These events demarcate the location of the Elmore Ranch fault, and terminate to the northeast roughly at the study area. Events occurring after the second shock are shown by octagons. Hachuring on Superstition Hills fault shows approximate extent of surface rupture during the sequence. Focal mechanisms for mainshocks from Bent et. al. (1989). Figure modified from Magistrale et. al. (1989). 
during the study period they provide a unique set of data to further evaluate seismicity within the Salton Sea geothermal field.

Extensive work has been done to characterize the rupture process in the Superstition Hills Sequence. Several studies indicate that rupture on the Superstion Hills fault consisted of a complex rupture with at least two subevents (Bent et. al., 1989; Larsen et. al., 1992; Frankel and Wennerberg, 1989; Magistrale et. al., 1989; Sipkin et. al., 1989; and Wald et. al., 1990).

The 1987 Elmore Ranch earthquake (first event) occurred on a vertical or near vertical fault striking approximately $40^{\circ}$ (Sipkin et. al., 1989; Bent et. al., 1989; Larsen et. al., 1992). Surface rupture on the fault splayed into several strands and slip was highly variable along strike (Hudnut et. al., 1989a). Creepmeters measured 13mm of left-lateral slip on the Elmore Ranch fault (McGill et. al., 1989). Hudnut et. al., (1989b) reported a total slip during 1987 of $150 \pm 20 \mathrm{~mm}$, which is comparable to the amount of slip that has occurred in the last 330 years.

Source parameter studies suggest rupture on the near vertical Superstition Hills fault (second event) varied in strike from $300^{\circ}$ to $320^{\circ}$ (Bent et. al., 1989; Larsen et. al. 1992; and Sipkin, 1989). The variability in strike arises in part from the complexity in rupture. Bent et. al. (1989) found that the two subevents associated with the Superstion Hills rupture had a strike of $305^{\circ}$ and $320^{\circ}$, respectively, for the first and second subevents. Creepmeters measured $39.8 \mathrm{~mm}$ of coseismic right-lateral slip on the Superstition Hills fault with another $40.2 \mathrm{~mm}$ of slip by August 3, 1988 (McGill et. al., 1989). Historic information on slip for the Superstition Hills fault indicate a total of 1106 
$\pm 50 \mathrm{~mm}$ slip in the last 330 years with approximately $497 \pm 20 \mathrm{~mm}$ occurring during the 1987 rupture, which had about $311 \mathrm{~mm}$ of coseismic slip (Hudnut and Sieh, 1989).

Hudnut and Sieh (1989) also reported that the Superstition Hills fault showed increased aseismic slip events following major earthquakes within the Imperial Valley. Triggered slip is not uncommon in the Imperial Valley. The two mainshocks of the Superstition Hills Sequence triggered slip on the Coyote Creek, Imperial, and southern San Andreas faults (McGill et. al., 1989). More details of the rupture properties of the two mainshocks will be discussed later in the context of Coulomb stress analysis.

The seismicity of the Salton Sea geothermal field is characterized by small, $\mathrm{M} \leq$ 1.5, daily sporadic events and swarm activity (Gilpin and Lee, 1978). Focal depths observed within the geothermal field are shallow, with the majority of focal depths ranging in depth from about 0.5 to $3.5 \mathrm{~km}$ (Gilpin and Lee, 1978). The lack of deeper seismicity attests to the high heat flow observed within the area. The source of earthquake activity within the geothermal field is due to hydraulic fracturing, magmatic processes, and tectonic processes (Younker et. al., 1982). The focal mechanisms within the area suggest regional right lateral motion with local extension on leaky transform faults (Gilpin and Lee, 1978 and Younker et. al. 1982). Gilpin and Lee (1978) found that focal mechanisms within the geothermal field were poorly constrained due to lack of data, but favored a system of en-echelon, right-lateral, strike-slip, leaky transform faults on which most of the swarm activity occurred. 


\section{CHAPTER 3}

\section{Data and Methods}

\section{Section 3.1 Microearthquake Survey}

Seventeen 3-component digital seismograph stations were operated at the Salton Sea Geothermal Field (SSGF) by Lawrence Livermore National Laboratory (LLNL) as part of the Salton Sea Scientific Drilling Project (Figure 3.1). These digital seismographs were operated from September 15, 1987 to September 30, 1988 and recorded more than 700 earthquakes within or near the SSGF. During this time Unocal maintained 7 verticalcomponent digital seismograph stations (Figure 3.1) which recorded over 150 events due to a lower signal to noise ratio than LLNL seismograph stations. More than 200 events from these seismic networks were used in this study.

The data, however, are about $75 \%$ incomplete, placing constraints on the information that can derived from these data. Waveforms were only available for 48 events that occurred from the beginning of the study period to November 25, 1987. LLNL has lost the original waveforms for this data set from their computer archives; thus the data set used in this study is now the most complete data set available from the seismograph deployment by LLNL. Because waveforms were unavailable for most of the data, phase picks provided with the data set had to be relied upon without verification. Examination of the limited waveform data suggests a picking error of 0.1 seconds 


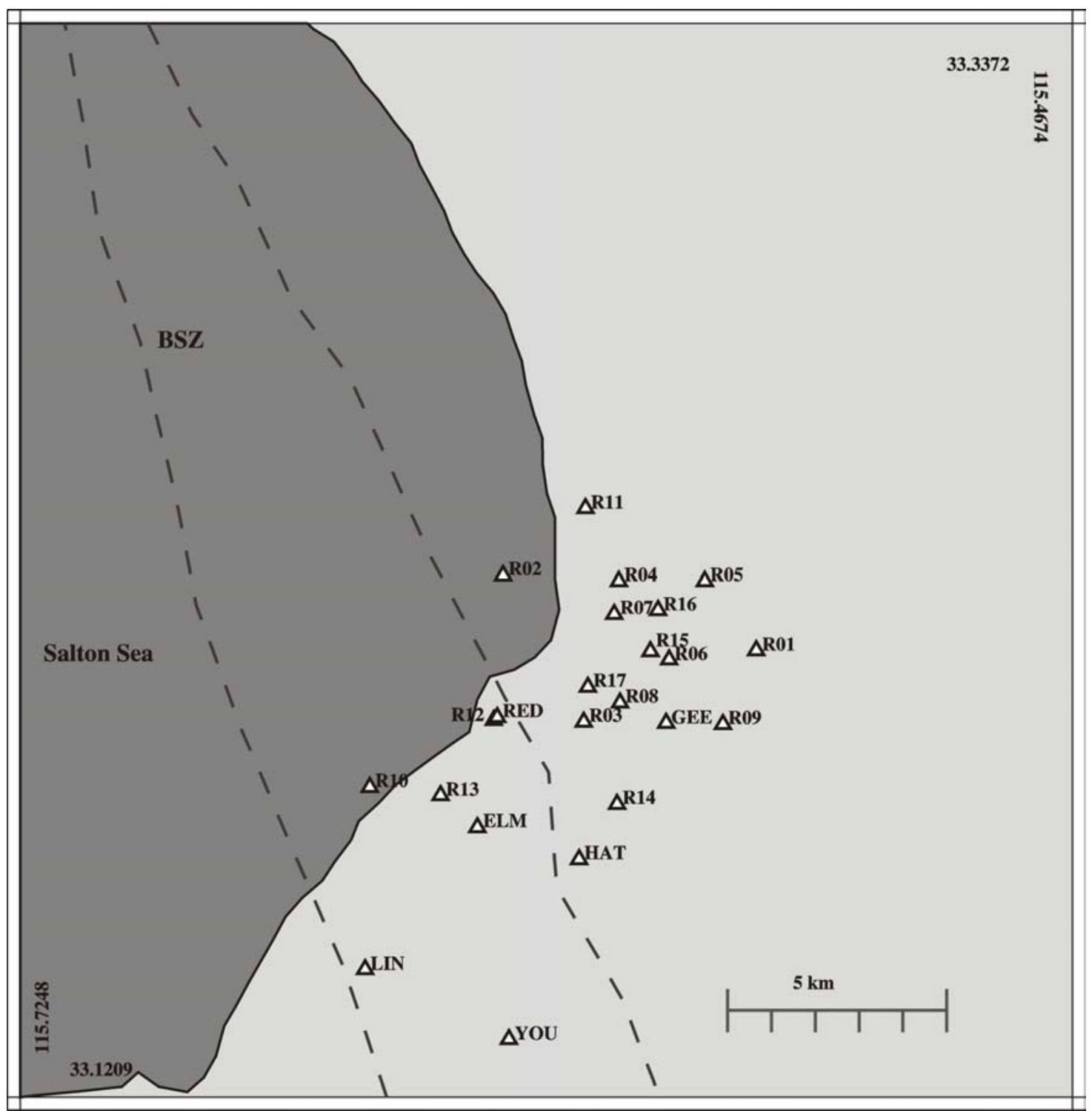

Figure 3.1. Station location map for stations used in microearthquake study. R01 through R17 were stations monitored by LLNL during the study period. ELM, HAT, LIN, YOU, and RED were all stations operated by Unocal. High resolution coastline data for the Salton Sea were not used for any location plots, thus giving the appearance of two seismic stations apparently located in the water, which is not the case. Triangle symbol will be used to represent location of seismic stations throughout the remainder of the text. 


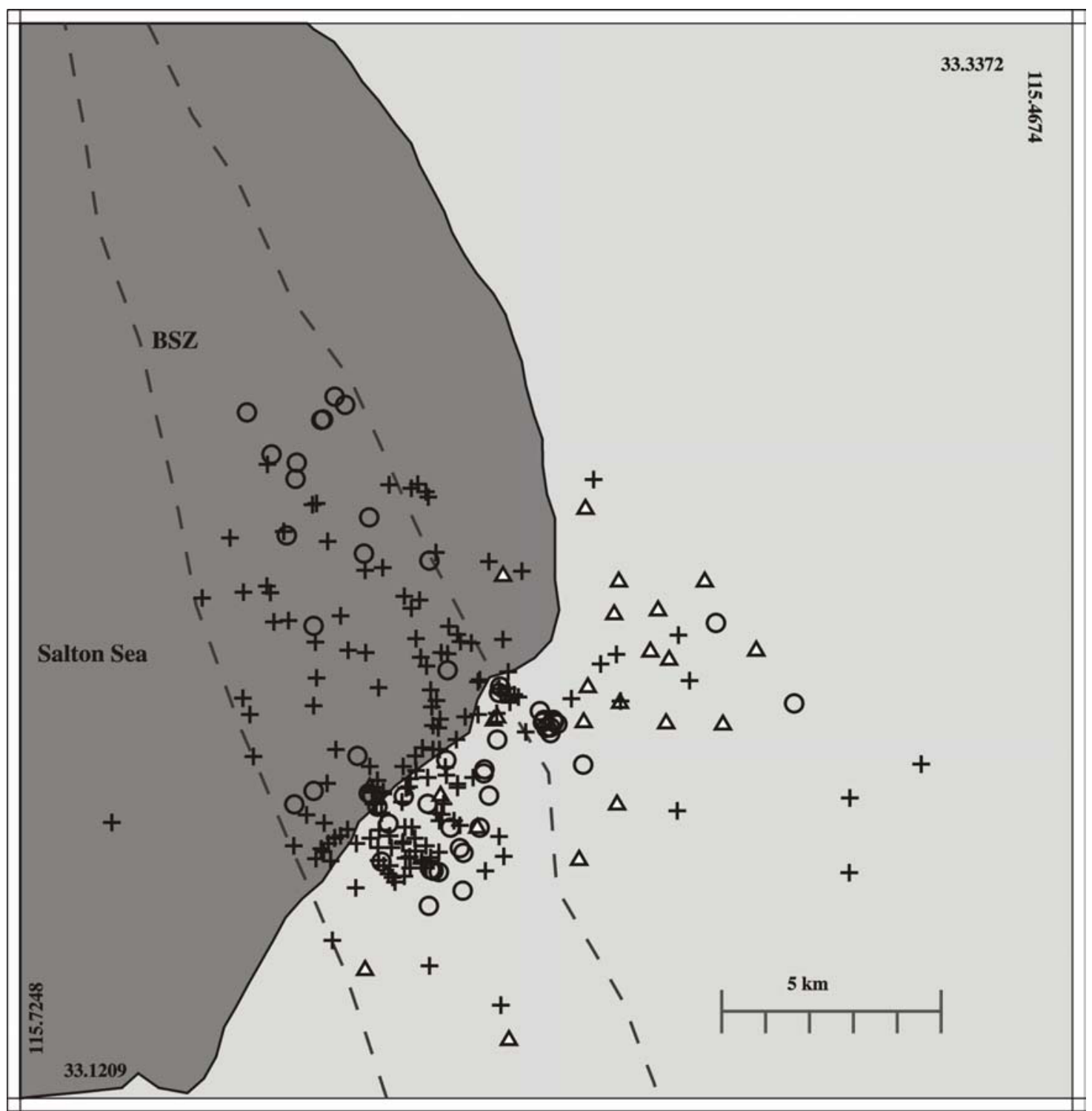

Figure 3.2. Hypocenter location map. Open circles indicate earthquakes that have associated waveform data and crosses indicate earthquakes for which no waveforms exist. 
and accurate polarity measurements. Figure 3.2 shows earthquakes that had available waveforms.

Another problem with the data set is that most of the microearthquakes were located outside of the seismic network. This yields high azimuthal gaps for most of the earthquakes used in this study. Locations programs are still able to obtain reasonable focal depths because most of the seismicity still lies within a few focal depths of seismograph stations. Some digital seismographs did not record events or had poor data for significant portions of the study period. These stations include R01, R10, R11, R13, R14, R15, R16, and R17 (Figure 3.1). Poor station operation limits the number of observations per earthquake, and also limits the amount of information that can be extracted from the data set.

\section{Section 3.2 Hypoinverse}

Hypoinverse is FORTRAN program for locating earthquakes that is described by Klein (2000). Hypoinverse locations were used as a comparison for all locations obtained from the different location methods used in this thesis, and also were quite often used as initial input to different models. Hypoinverse locations are calculated by iterating for the minimum RMS travel-time residuals. The solution is solved as a least squares single value decomposition (SVD) problem where all eigenvalues that do not contain the origin time, latitude, longitude and depth are neglected after each iteration. Errors reported by Hypoinverse are the largest error in the horizontal direction and the error in the vertical location, as estimated from the covariance matrix of the eigenvalues. 
This method for locating earthquakes is widely used and was selected as a beginning point due to the author's familiarity with the program.

Section 3.3 Inversion for 1-D velocity model

The relocation of hypocenters for the microearthquakes recorded within the SSGF required development of a suitable velocity model. The initial model is based on refraction data recorded (Figure 2.2 and 2.3) near the geothermal field (Fuis. et. al., 1982). This model was then used as a starting model for a 1-D velocity inversion using VELEST (Evans et. al., 1994) available from the United States Geological Survey (USGS). Kissling et. al. (1994) recommend starting with a model based on available refraction data and provide a guide to reaching a minimum 1-D velocity model. Phase arrivals for 199 earthquakes were located in Hypoinverse using the initial velocity model of Table 3.1 and Figure 3.3. Initial locations and phase arrivals reported from Hypoinverse were then used as input to the VELEST 1-D inversion. A Vp/Vs ratio of 1.73 was assumed for the starting velocity models. This value does not seem unreasonable when compared to results from the vertical seismic profile data for California State 2-14 (Daley et. al., 1988). The VELEST inversion code does invert for both $\mathrm{S}$ and $\mathrm{P}$-wave velocities if both $\mathrm{P}$ - and $\mathrm{S}$-wave arrivals are input. S-wave arrivals were given half the weight of P-wave arrivals. Station delays were not known for this data set, but were included in the inversion process at one-tenth the weight of layer velocities. No observable pattern to station delays reported by the inversion code can be 
Table 3.1. Velocity models with depth to top of velocity layer and the associated velocity extending to the next depth listed. Depths below $13 \mathrm{~km}$ were considered as a homogeneous half-space with the associated velocity.

\begin{tabular}{|c|c|c|c|c|c|c|c|}
\hline \multicolumn{2}{|c|}{ Initial Model } & \multicolumn{2}{|c|}{ VELEST $1 \mathrm{~km}$ spacing } & \multicolumn{2}{|c|}{ VELEST $0.5 \mathrm{~km}$ spacing } & \multicolumn{2}{|c|}{ VELEST with low velocity } \\
\hline Depth (km) & Velocity $(\mathrm{km} / \mathrm{s})$ & Depth $(\mathrm{km})$ & Velocity $(\mathrm{km} / \mathrm{s})$ & Depth (km) & Velocity $(\mathrm{km} / \mathrm{s})$ & Depth (km) & Velocity $(\mathrm{km} / \mathrm{s})$ \\
\hline 0.0 & 2.00 & 0.0 & 2.02 & 0.0 & 1.99 & 0.0 & 1.86 \\
\hline \multirow[b]{2}{*}{1.0} & \multirow[b]{2}{*}{2.50} & \multirow[b]{2}{*}{1.0} & \multirow[b]{2}{*}{2.46} & 0.5 & 1.99 & 0.5 & 1.86 \\
\hline & & & & 1.0 & 2.15 & 1.0 & 1.98 \\
\hline \multirow[b]{2}{*}{2.0} & \multirow[b]{2}{*}{3.00} & \multirow[b]{2}{*}{2.0} & \multirow[b]{2}{*}{2.98} & 1.5 & 2.44 & 1.5 & 2.35 \\
\hline & & & & 2.0 & 3.13 & 2.0 & 3.32 \\
\hline \multirow[b]{2}{*}{3.0} & \multirow[b]{2}{*}{4.50} & \multirow[b]{2}{*}{3.0} & \multirow[b]{2}{*}{4.26} & 2.5 & 3.23 & 2.5 & 3.34 \\
\hline & & & & 3.0 & 4.52 & 3.0 & 4.54 \\
\hline \multirow[b]{2}{*}{4.0} & \multirow[b]{2}{*}{5.00} & \multirow[b]{2}{*}{4.0} & \multirow[b]{2}{*}{4.97} & 3.5 & 4.60 & 3.5 & 4.54 \\
\hline & & & & 4.0 & 4.96 & 4.0 & 5.01 \\
\hline \multirow[b]{2}{*}{5.0} & \multirow[b]{2}{*}{5.50} & \multirow[b]{2}{*}{5.0} & \multirow[b]{2}{*}{4.97} & 4.5 & 4.99 & 4.5 & 5.09 \\
\hline & & & & 5.0 & 5.00 & 5.0 & 4.99 \\
\hline \multirow[b]{4}{*}{7.0} & \multirow[b]{4}{*}{6.00} & \multirow[b]{4}{*}{7.0} & \multirow[b]{4}{*}{5.28} & 5.5 & 5.00 & 5.5 & 4.97 \\
\hline & & & & 6.0 & 5.00 & 6.0 & 4.99 \\
\hline & & & & 6.5 & 5.00 & 6.5 & 5.01 \\
\hline & & & & 7.0 & 5.29 & 7.0 & 5.30 \\
\hline \multirow[b]{3}{*}{10.0} & \multirow[b]{3}{*}{6.50} & \multirow[b]{3}{*}{10.0} & \multirow[b]{3}{*}{6.05} & 8.0 & 5.30 & 8.0 & 5.30 \\
\hline & & & & 9.0 & 5.30 & 9.0 & 5.30 \\
\hline & & & & 10.0 & 6.05 & 10.0 & 6.05 \\
\hline \multirow[b]{3}{*}{13.0} & \multirow[b]{3}{*}{7.00} & & & 11.0 & 6.05 & 11.0 & 6.05 \\
\hline & & & & 12.0 & 6.05 & 12.0 & 6.05 \\
\hline & & 13.0 & 6.45 & 13.0 & 6.45 & 13.0 & 6.45 \\
\hline
\end{tabular}




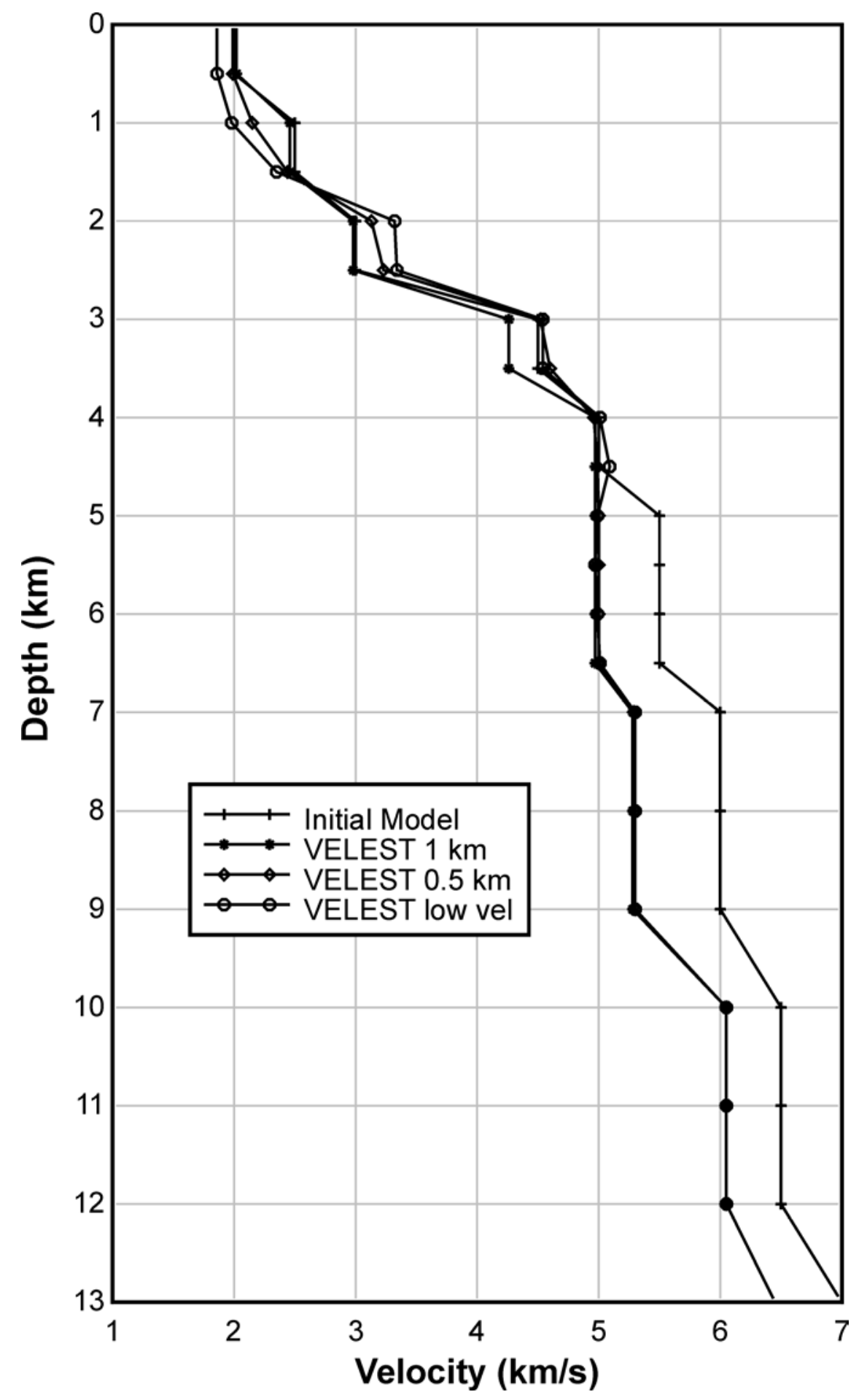

Figure 3.3. Velocity models listed in Table 3.1. 
observed except that the furthest north and south stations both have unusually high station delays (Figures 3.4 and 3.5).

An iterative approach towards finer resolution was applied to the inversion. The first inversion was done for one kilometer thick layers to a depth of $7 \mathrm{~km}$; below which thicker layers were used. VELEST took 29 iterations to reach an RMS minimum of $0.3 \mathrm{~s}$. The layer thickness was then reduced to half a kilometer and the output from the previous inversion was used as the starting model. This inversion took 5 iterations to reach a minimum RMS of $0.07 \mathrm{~s}$. After 6 iterations the RMS did not improve when the inversion was modified to allow for low velocity layers. All output velocity models are shown in Table 3.1 and Figure 3.3.

Even spacing was used instead of searching for actual velocity boundaries in order to ease input into an evenly spaced three-dimensional grid for further analysis. Figure 3.6 shows the final ray coverage, velocity profile, and hypocenter locations obtained from the inversion. Ray coverage suggest that resolution of velocities below 6 or $7 \mathrm{~km}$ depth is poor. The average RMS for residuals of events in the velocity inversion was 0.04 seconds with a standard deviation of 0.06 seconds, values that are well within the estimated picking errors of 0.1 seconds. The velocity model obtained from this inversion was used for all microearthquake locations in this study and formed the basis for generating a 3-D velocity model. 


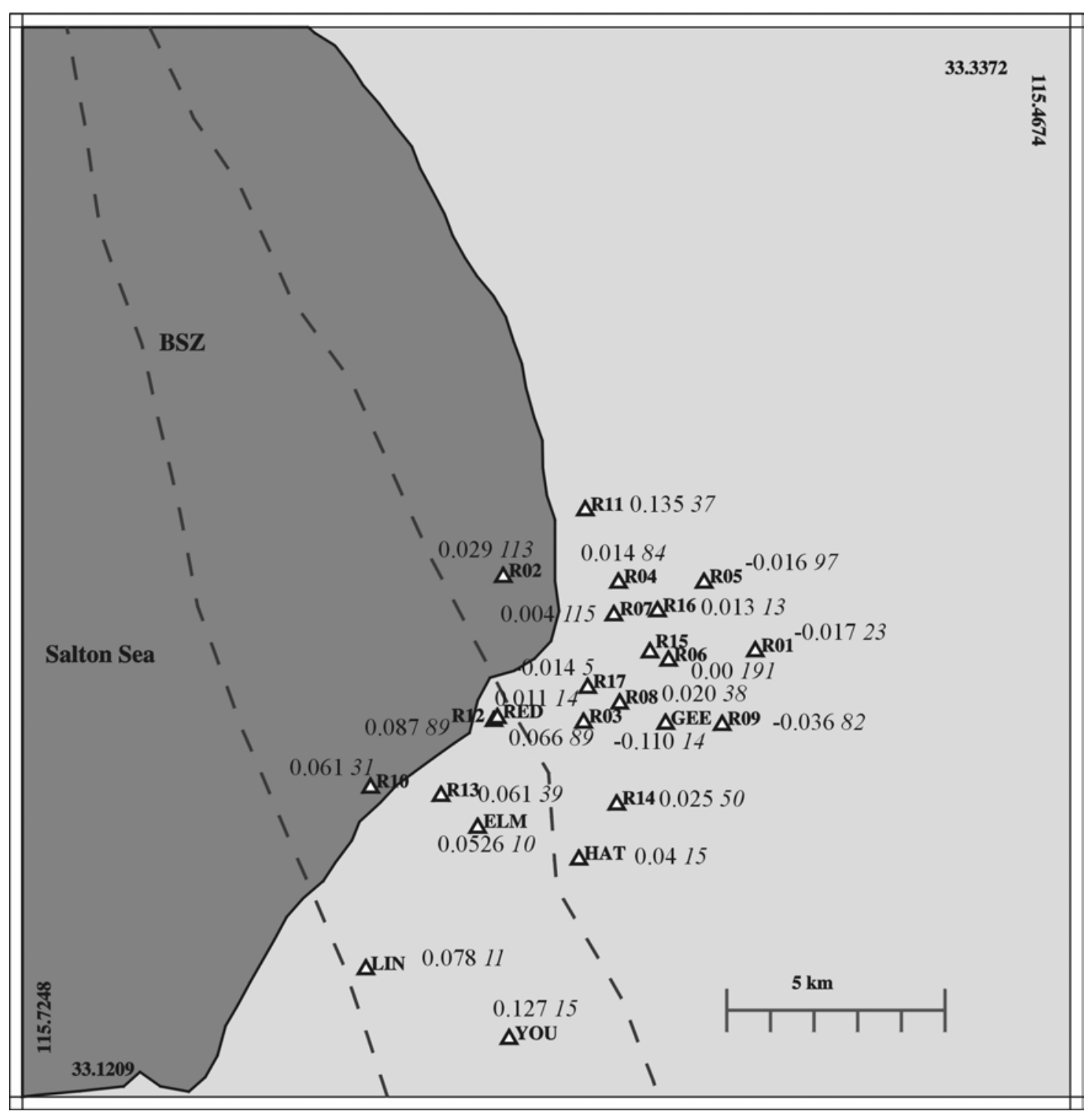

Figure 3.4. - P-wave station delays reported by 1-D inversion VELEST. Station delays and number of observations (in italics) are reported near each station. Station R15 had no P-wave observations. 


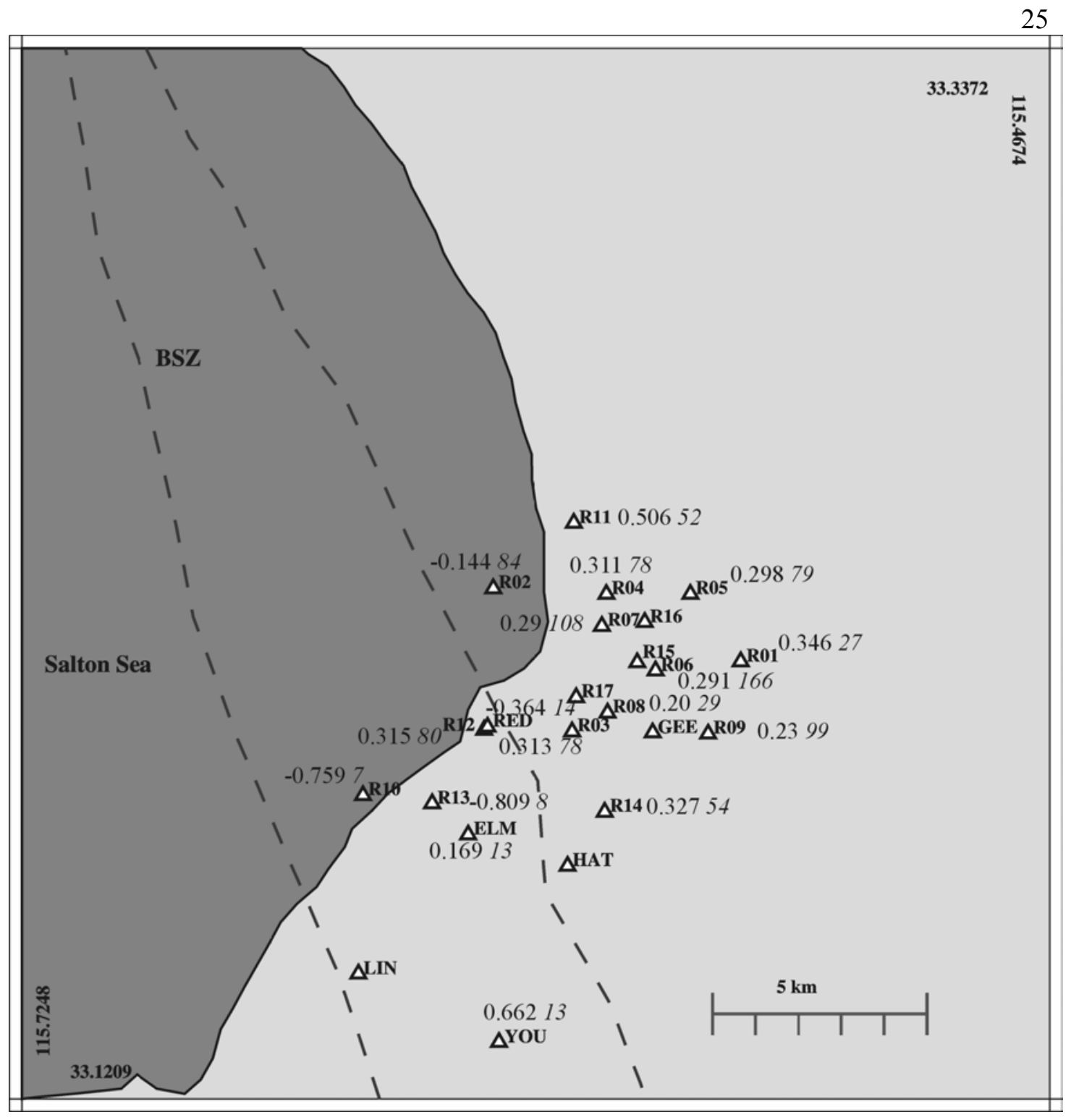

Figure 3.5. S-wave station delays reported by 1-D inversion VELEST. Station delays and number of observations (in italics) are reported near each station. Stations R15, R16, R17, GEE, HAT, and LIN had no S-wave observations. 

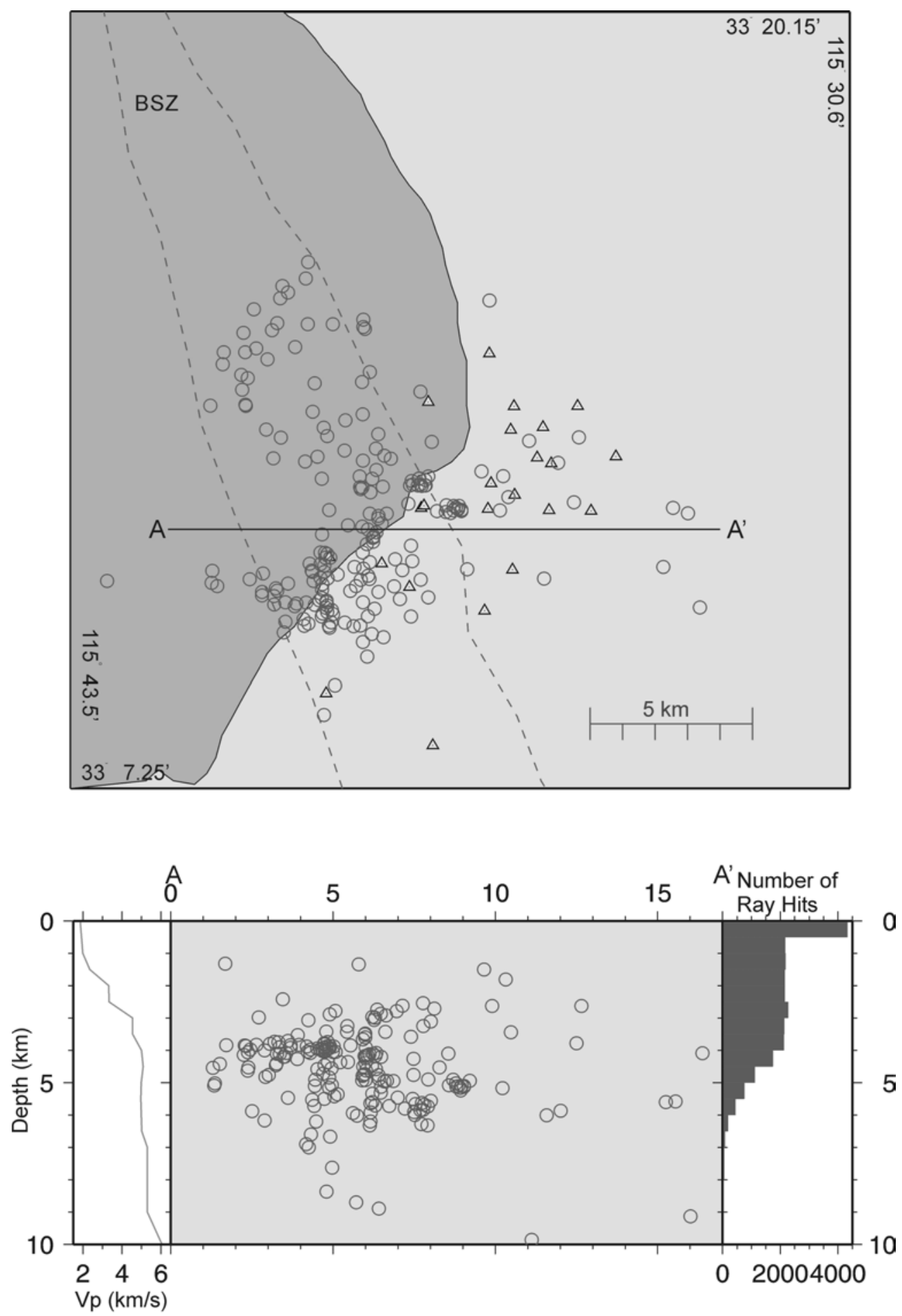

Figure 3.6. Final ray coverage, velocity profile and hypocenter locations obtained for 1$\mathrm{D}$ inversion using VELEST. 
Section 3.4 Estimation of anisotropy from well logs

Seven well logs from the SSGF were used to assess the amount of seismic anisotropy within the geothermal field (Figure 3.7). These well logs were digitized at 0.5-ft spacing. Lithologies observed within the wells are generally finely bedded shales and siltstones with small lenses of clean sandstone. These lithologies are mainly associated with deltaic sediments from the Colorado River and inland seas (Sharp,1982 and Elders and Sass, 1988). Since a number of the wells within the geothermal field had not been logged using a sonic tool, velocities had to be related to the deep induction logs available for all but two well logs obtained by the author. Two wells had sonic logs as well as induction logs, the Hudson Ranch Unit 1, and the California State 2-14, which was the well used for the Salton Sea Scientific Deep Drilling Project as described by Elders and Sass (1988). Appendix A lists information for each well, including their associated $\log$ s.

Well logs from Hudson Ranch Unit 1 visually correlate well. This correlation was used to convert induction logs to pseudo-transit time logs. First the transit time data for Hudson Ranch Unit 1 was plotted against induction data and a standard least squares linear relationship between the two data sets was calculated. Although this worked well for the Hudson Ranch well, the relationships yielded poor pseudo-transit time logs for many of the other wells. Therefore a complex function that matches the general features of the relationship between induction and transit time data for the Hudson Ranch well was found through simple trial and error. A bounding function was applied so that transit times calculated from the relationship would not be slower than the speed of sound in 


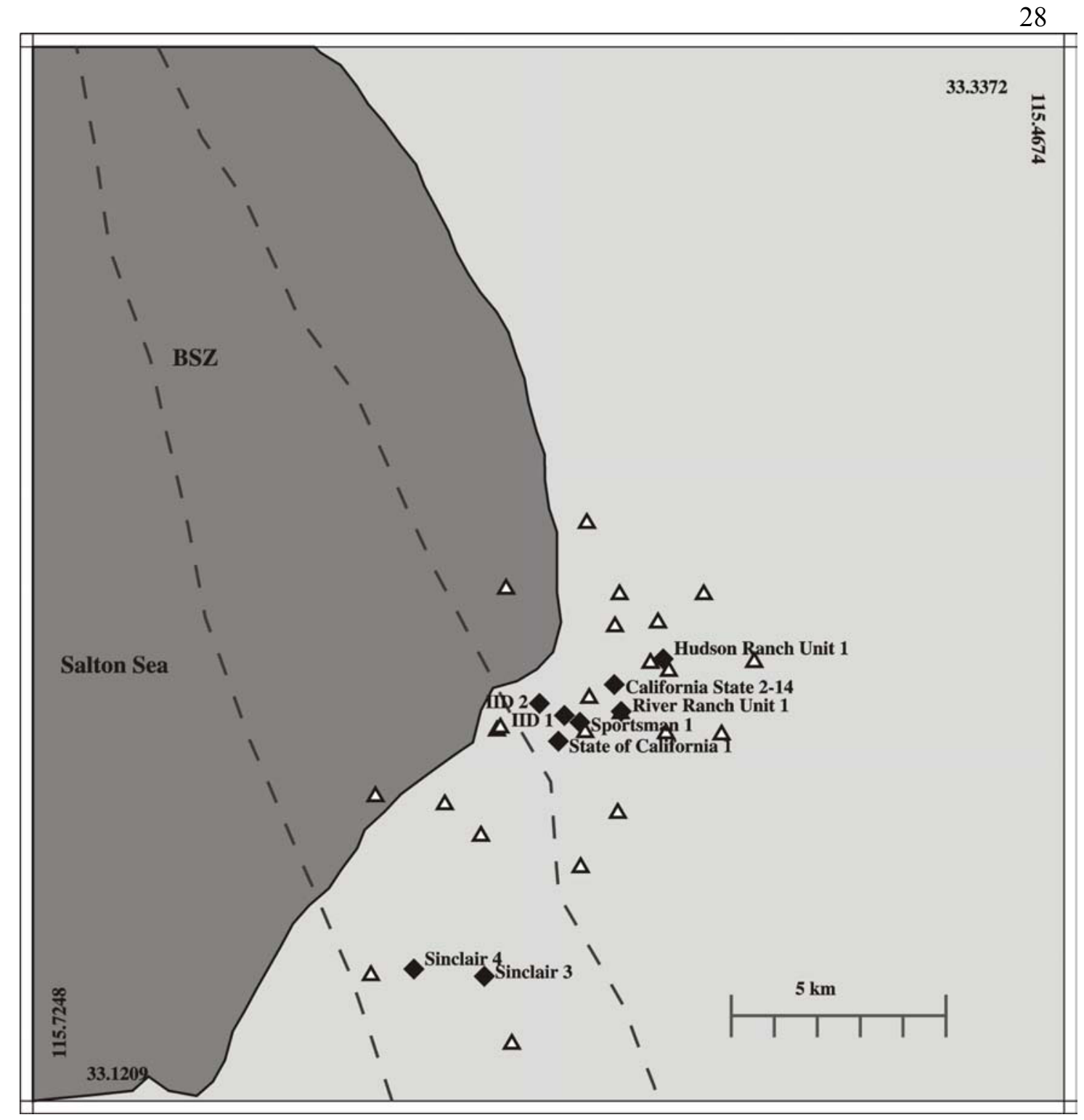

Figure 3.7. Location of wells (black diamonds) used in the assessment of anisotropy of the Salton Sea Geothermal Field. Wells Sportsman 1 and I.I.D. 1 do not have induction or sonic logs associated with them and were not used in this study, but are plotted for reference. Note position of wells relative to the seismicity shown in Figure 3.2. Again, triangles indicate the location of seismic stations. 
water. The resulting relationships were then used to convert other deep induction logs to pseudo-transit time logs.

Figures 3.8a-b show the deep induction log data versus transit times for the Hudson Ranch Unit 1 logs. No similar relationship could be obtained for the California State 2-14 well (Figure 3.9). Thus all pseudo-transit time calculations were made using the relationship obtained at Hudson Ranch Unit 1. Pseudo-transit time logs for other wells can be seen in Appendix A. In general there is less scatter in the conductivity deep induction logs, which were used for the calculation of anisotropy estimates when available. A strong correlation can be seen between the conductivity deep induction logs and deep induction logs.

Applying the pseudo-transit time relationship from the Hudson Ranch log to all other induction data makes several assumptions about the character of formations within the Salton Sea Geothermal Field. First, the water saturation and chemistry cannot vary laterally between wells. The amount of water present in the formation and the amount of dissolved ions will have the largest effect on the induction data. If Younker et. al. (1982) are correct, the largest component of fluid convection occurs laterally beneath the lithologic cap and is limited vertically. This large-scale lateral convection would hopefully maintain the wells at similar pore water chemistry.

Second, the thermal regime must not vary laterally. The thermal regime controls some of the lithological parameters since metamorphism begins at depths of 1,200 to 1,800 meters (Paillet and Morin, 1988). The thermal regime at a well also affects the chemistry of its formation waters. Younker et. al. (1982) shows that most wells within 

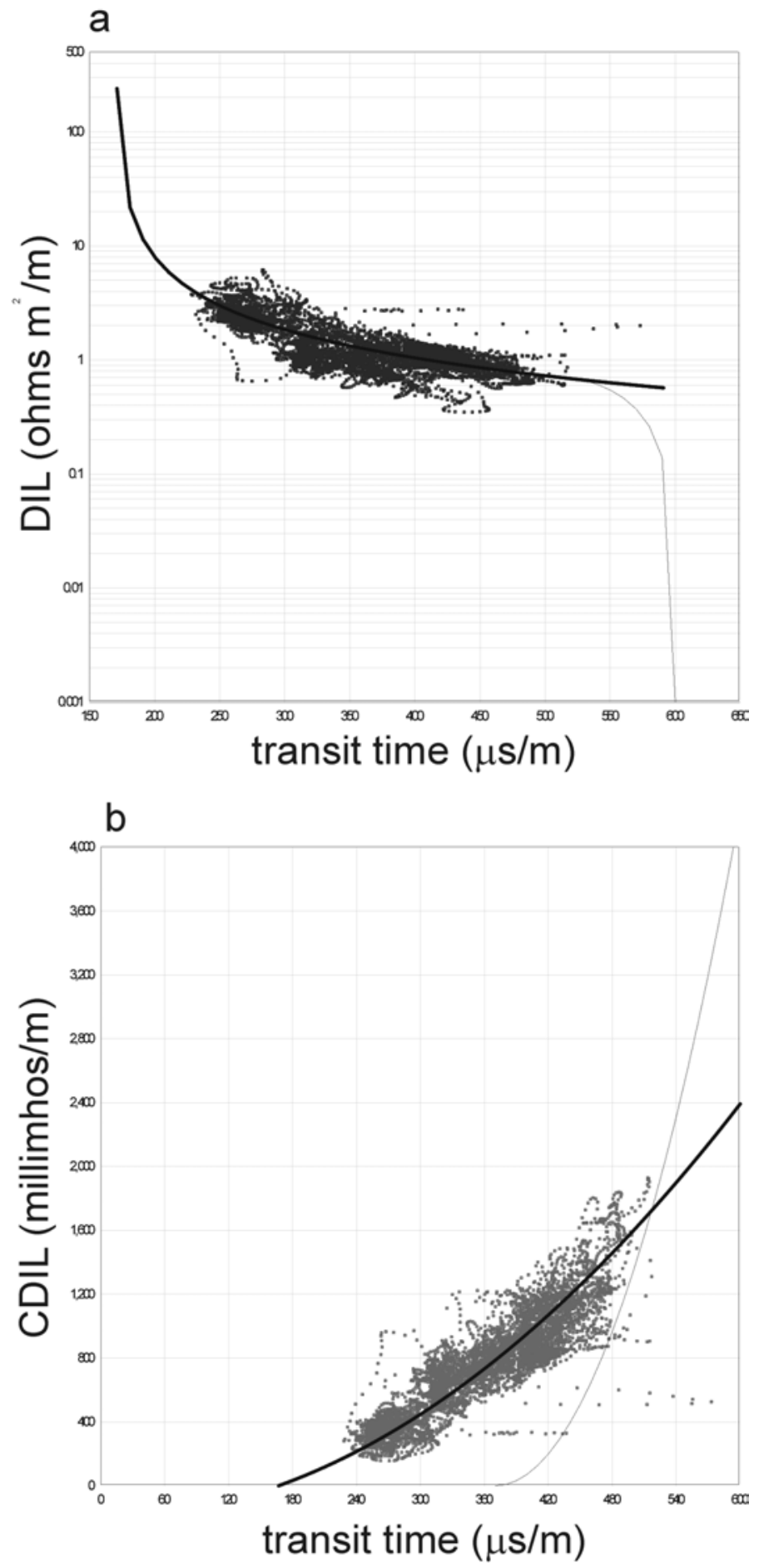

Figure 3.8. Hudson Ranch Unit 1 deep induction correlation functions used to describe induction verses transit time logs relationships: a) Deep Induction Log (DIL), b) Conductivity Deep Induction Log (CDIL). 


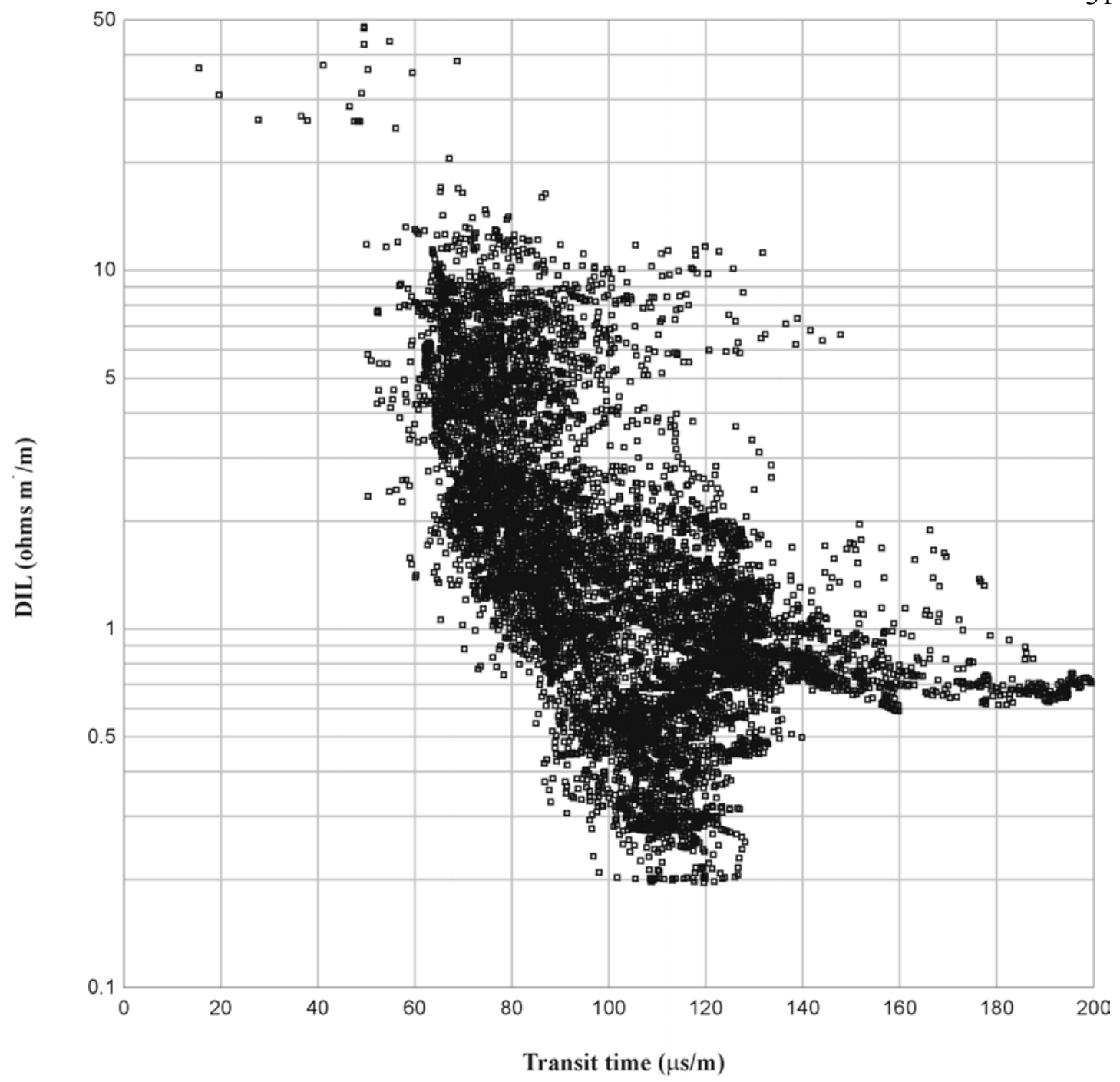

Figure 3.9. California State 2-14 deep induction log verses transit time. Scatter in the data made finding a meaningful relationship applicable to other logs difficult. 
the geothermal field have similar thermal gradients and temperature. However, Kasameyer et. al. (1989) show that this may be questionable because they map three thermal anomalies within the broader high heat flow region. These thermal anomalies are not sampled by wells, but could significantly affect reservoir characteristics at the wells. The Sinclair wells located toward the southern end of the field have dramatically different thermal profiles (Younker et. al., 1982). Finally, dipping beds and anisotropy will also affect the use of induction data as a sonic proxy in other wells.

As mentioned previously, no good correlation could be made between transit time logs and the induction logs for the State 2-14 well. Paillet and Morin (1988) also noted a discrepancy between induction data and the sonic log, which they attributed to emergent first arrivals during sonic logging being mispicked during the recording process for the sonic log. However, they found good agreement for the interval from 1200 to $1800 \mathrm{~m}$ depth. This is the range where the pseudo-transit times from conductivity deep induction logs calculated from the Hudson Ranch Unit 1 correlation correspond quite well to the sonic log data at State 2-14.

Paillet and Morin (1988) suggest that transit times are too slow for previously determined velocities measured at the Salton Sea geothermal field, for the interval above $1200 \mathrm{~m}$ depth. However, the sonic log yields velocities at these depths that are quite similar to those obtained from the velocity inversion of micro-earthquakes in this study (Figure 3.6). Since pseudo-transit time logs correspond well to transit time logs at depths greater than about $1200 \mathrm{~m}$ in the State 2-14 well, this suggests that either the sonic log or the induction logs had an interval at shallow depths that was unusable. A distinct overpressured zone is observable on the State 2-14 sonic log, indicating that the induction 
data may have had a poor response in the interval above $1200 \mathrm{~m}$ depth, the depth that corresponds to the overpressured zone. The author chose to use the sonic log rather than pseudo-transit time data for the calculation of anisotropy estimates for State 2-14.

Velocity profiles from psuedo-transit time, transit time logs, and velocity inversion profile are shown in Figure 3.10. The general shapes of the velocity profiles approximate the $\mathrm{v}_{\mathrm{p}}$ profile determined from the 1-D velocity inversion. Velocity profiles for wells are consistently higher than the 1-D velocity model especially at increasing depth with the exception of well I.I.D. 2. Velocity profiles indicate an overpressured zone that is fairly pervasive throughout the SSGF. This overpressured zone can be observed for wells Hudson Ranch Unit 1, California State 2-14, Sinclair 4, State of California 1, and possibly River Ranch 1 . The velocity profiles show great variability even between closely spaced wells. This high variability, nearly $\pm 30 \%$ from a roughly average velocity curve, indicates that the assumptions made in the pseudo-transit time calculations may not be correct. Variability increases as well depth increases and profiles fluctuate dramatically over very short intervals. All velocity profiles become questionable at the bottom of the logged well, indicating there may be a depth dependence that has not been factored into the relationship between transit-time and deep induction logs.

Sonic log and pseudo-transit time data were then used to calculate the amount of anisotropy within defined intervals. Waveforms obtained during the study period had corner frequencies of over $20 \mathrm{~Hz}$. Assuming the velocities shown in Table 3.1, this 


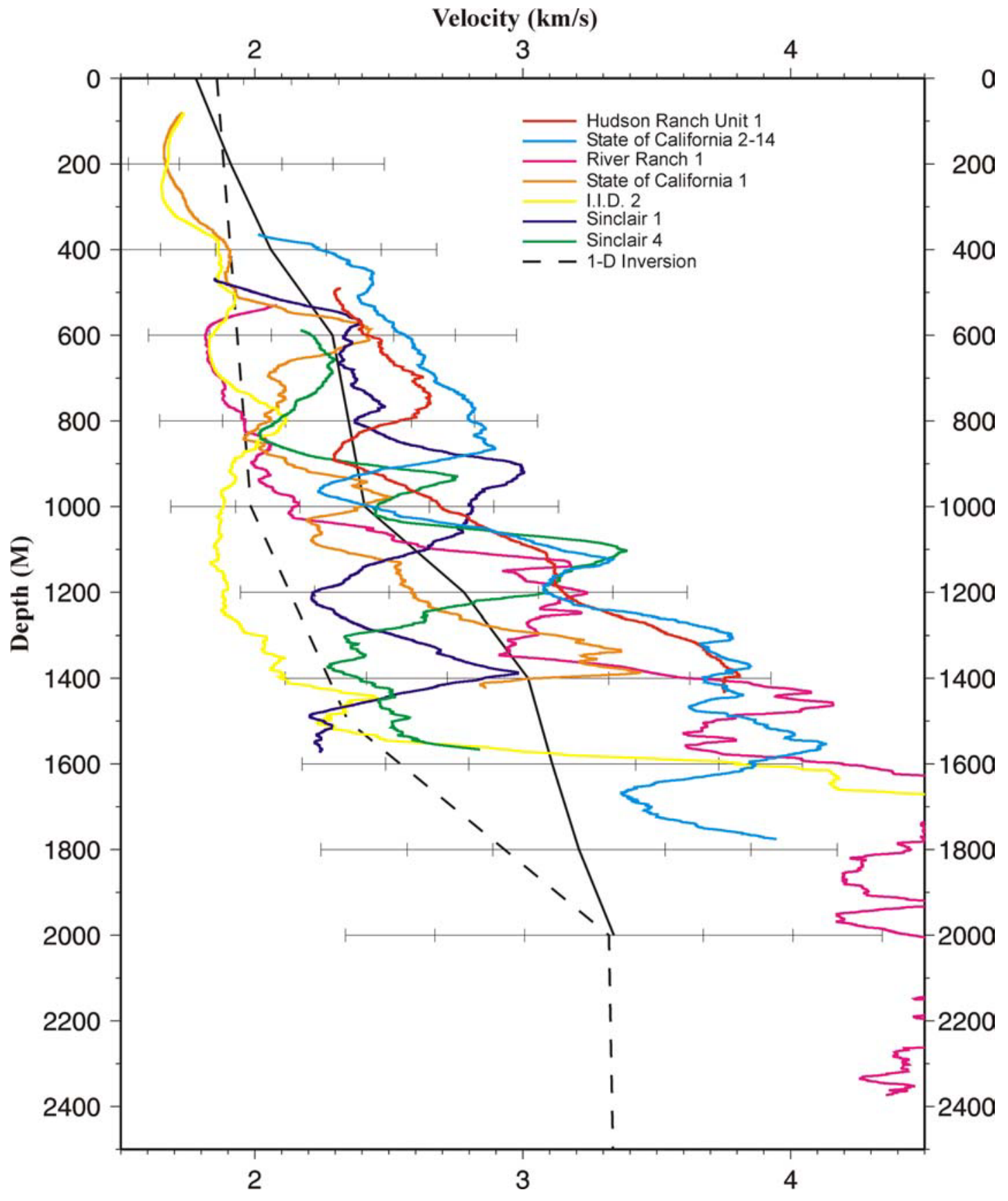

Figure 3.10. Velocity profiles from sonic logs (Hudson Ranch and State 2-14), when available, or pseudo-transit time logs. The solid black line indicates rough average velocity profile for wells with 10,20 , and $30 \%$ error bars. The dashed line indicates velocity profile output from the 1-D VELEST inversion. 
corresponds to a wavelength of about $400 \mathrm{~m}$. Therefore, interval lengths for calculating anisotropy were chosen to approximate what the seismic waves sample. The boundaries between intervals were then defined keeping this criterion in mind and were based on distinct changes in the character of the logs, available geologic data, and characteristics of intervals in nearby wells. Intervals for each well can be seen in Figure 3.11 and individually for each well in Appendix A. Selection of well intervals was highly subjective, but provided a beginning point to examine anisotropy estimates.

Anisotropy estimates were calculated using the following method. Vertical slownesses from digitized logs were used to compute stiffnesses for 1-m thick intervals. Stiffness is defined as the velocity squared times the density, and compliance is the reciprocal of stiffness. An average of the stiffness (Voight Estimate) over the defined intervals provides an upper bound on the composite stiffness while an average of compliances (Reuss Estimate) provides a lower bound on the composite stiffnesses seen by the seismic wave (Hill, 1952). The Voight bound corresponds to an average vertical stiffness and the Reuss bound to an average horizontal stiffness for a layered medium. These bounds approximate only one component of the true anisotropy. Vertical slowness estimates assume layering extends laterally to a distance greater than one seismic wavelength. Densities used for calculation of stiffnesses were approximated using the State 2-14 density log, borehole gravimetry (Kasameyer and Hearst, 1988), and results from laboratory analysis of core from State 2-14 (Tarif et. al., 1988). To compare various density models available anisotropy estimates for intervals were calculated for the detailed density log and a general density curve interpolating between the points shown 


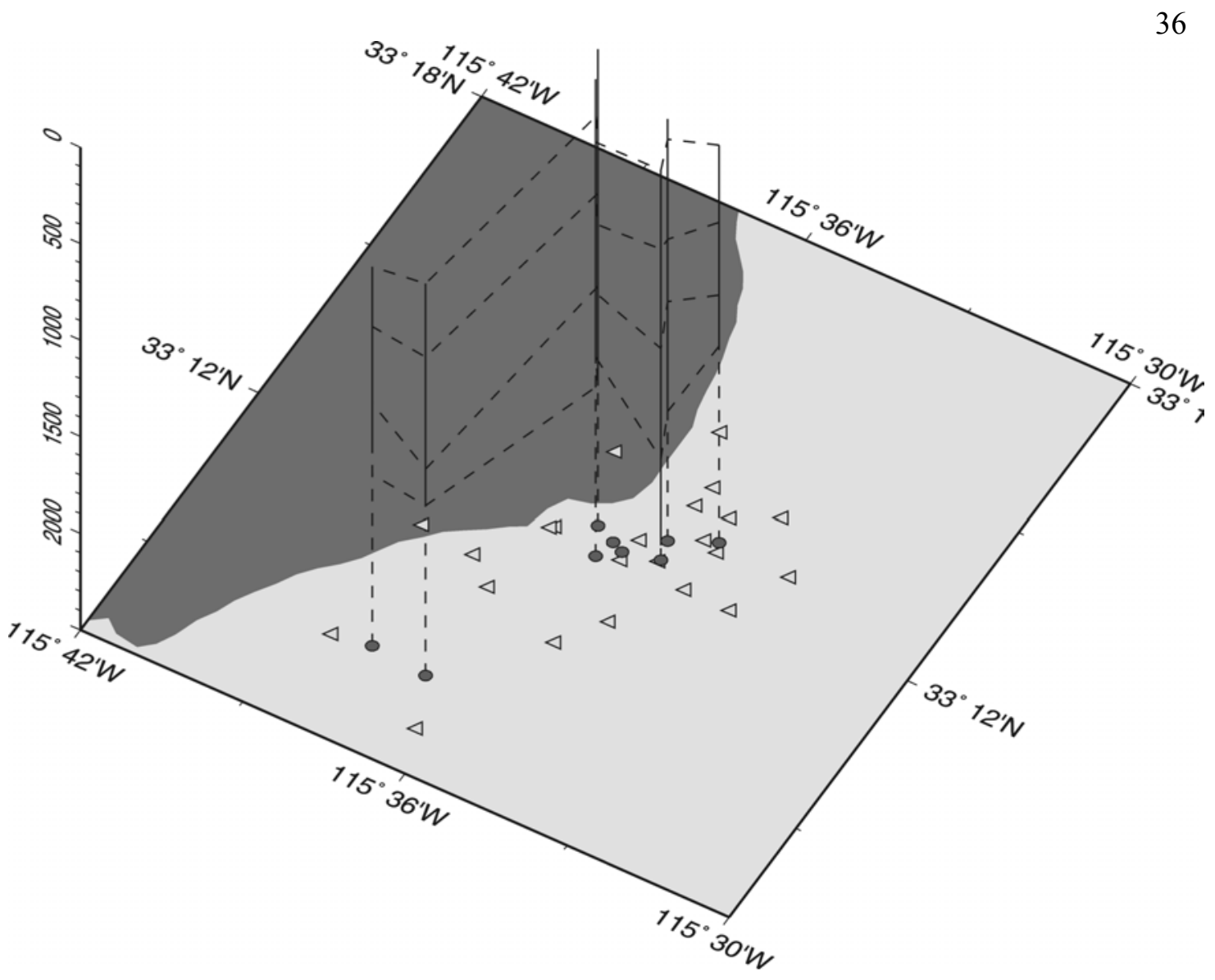

Figure 3.11. 3-D projection of well interval relationships for anisotropy analysis at the Salton Sea geothermal field. Pseudo-transit time logs plotted with well intervals can be seen in Appendix A. Solid circles are well locations, and triangles are seismometer locations. 
in Table 3.2. Anisotropy estimates between the detailed and general curves had less than a $1 \%$ difference in the amount of anisotropy within an interval. The general curve should be more suitable for calculation of anisotropy estimates in all wells. Results from the estimation of anisotropy for each well and its defined intervals are listed in Table 3.3. These results were then used to build a three-dimensional velocity model.

\section{Section 3.5 Location of microearthquakes with anisotropy}

Location of microearthquakes using a three-dimensional velocity model was attempted using a finite difference program similar to Nelson and Vidale (1990). This program searches a three-dimensional gridded volume and finds the global minimum travel time residuals employing several minimization criteria for residuals. In this case, the standard least squares method was used in this study. The capability to include calculations for travel times in anisotropic media in the location algorithm is based on methods described by Lecomte (1993). Earthquake location precision is finer than selected grid spacing, which for this study was $500 \mathrm{~m}$. Locations using the onedimensional isotropic case can be seen in Figures 3.12 and 3.13. A site-specific velocity model was constructed using results from the one-dimensional inversion with a $2 \%$ background seismic anisotropy and estimates of anisotropy from well logs. The anisotropy was added to the background to cause less of an abrupt boundary between the region of the study area contained by well $\log$ s and the rest of the study area. The $2 \%$ amount was chosen because it is near the lowest value for anisotropy observed in well 
Table 3.2. Generalized density profile for the Salton Sea Geothermal Field used in the calculation of anisotropy estimates.

\begin{tabular}{|c|c|}
\hline Depth $(\mathrm{km})$ & Density $\left(\mathrm{g} / \mathrm{cm}^{3}\right)$ \\
\hline 0 & 1.6 \\
\hline 200 & 2.0 \\
\hline 2000 & 2.7 \\
\hline 2500 & 2.8 \\
\hline
\end{tabular}

Table 3.3. Anisotropy estimates for well log intervals. Each interval is identified by the top of the intervals and the percent anisotropy calculated from the top of the interval to the top of the next interval.

\begin{tabular}{|l|r|c|}
\hline & Depth $(\mathrm{m})$ & \% Anisotropy \\
\hline Hudson Ranch Unit 1 & 440.4 & 5.06 \\
\cline { 2 - 3 } & 841.2 & 8.42 \\
\cline { 2 - 3 } & 1219.2 & 2.76 \\
\hline I.I.D. 2 & 30.5 & 0.34 \\
\cline { 2 - 3 } & 369.0 & 1.19 \\
\cline { 2 - 3 } & 779.2 & 3.80 \\
\hline River Ranch 1 & 1260.8 & 116.00 \\
\cline { 2 - 3 } & 480.4 & 5.68 \\
\cline { 2 - 3 } & 889.7 & 42.40 \\
\cline { 2 - 3 } & 1405.9 & 15.26 \\
\hline California State 2-14 & 1979.8 & 17.83 \\
\cline { 2 - 3 } & 314.0 & 9.77 \\
\cline { 2 - 3 } & 420.9 & 5.41 \\
\cline { 2 - 3 } & 938.5 & 17.16 \\
\hline State of California 1 & 1262.5 & 13.55 \\
\cline { 2 - 3 } & 31.1 & 0.48 \\
\cline { 2 - 3 } & 358.4 & 14.44 \\
\cline { 2 - 3 } & 782.6 & 16.75 \\
\hline Sinclair 3 & 1138.6 & 33.73 \\
\cline { 2 - 3 } & 471.3 & 6.41 \\
\cline { 2 - 3 } & 851.5 & 8.01 \\
\hline Sinclair 4 & 1433.5 & 7.16 \\
\cline { 2 - 3 } & 538.9 & 2.69 \\
\cline { 2 - 3 } & 848.9 & 22.81 \\
\hline \multirow{3}{*}{} & 1246.9 & 22.81 \\
\hline
\end{tabular}




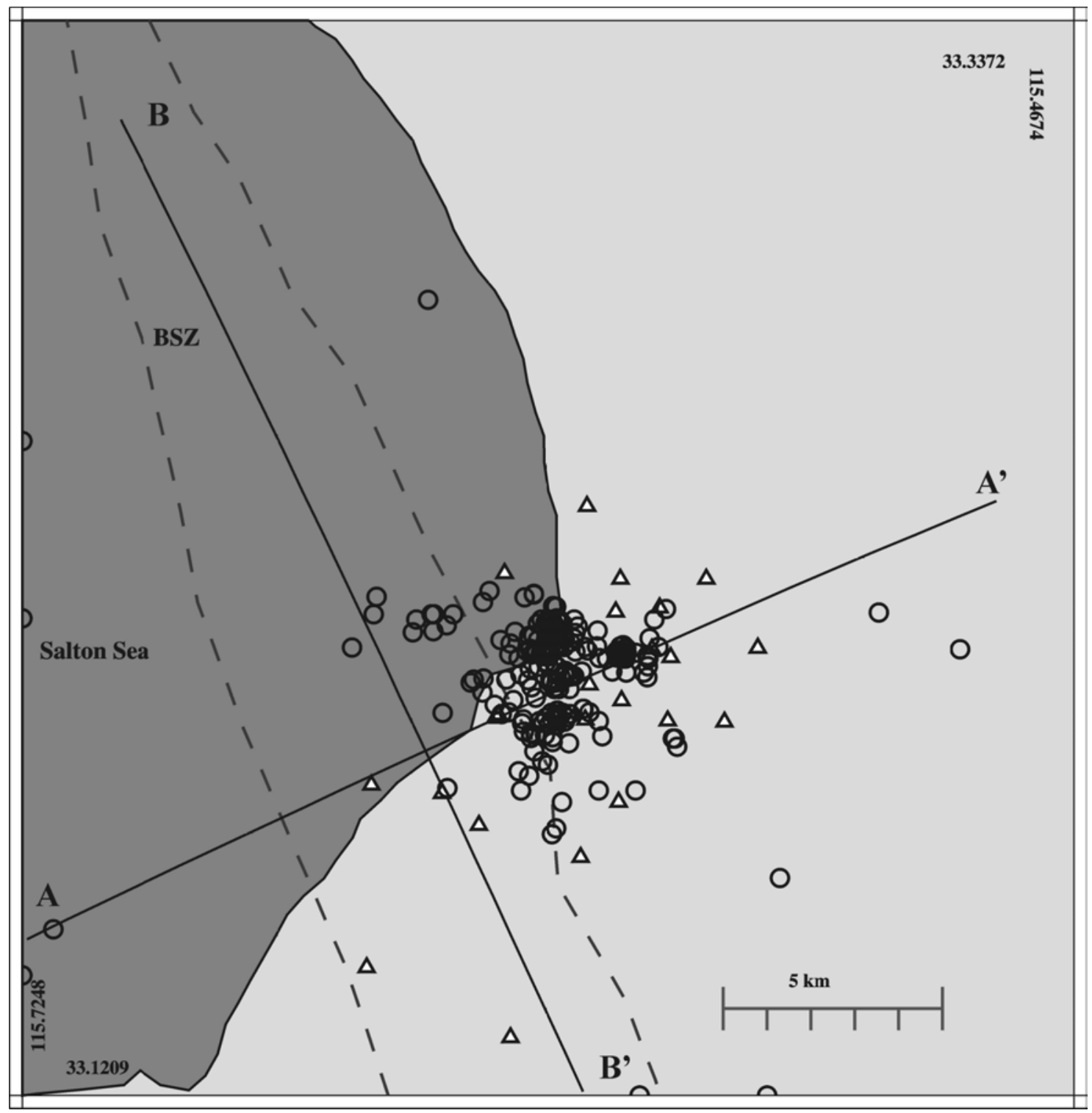

Figure 3.12. Earthquake locations using 1-D isotropic case from EQLOC2. Events have dramatically different locations than those calculated from other location methods. Locations are pulled in towards the center of the seismic station network. Cross-sections A to A' and B-B' are shown in Figure 3.13. 

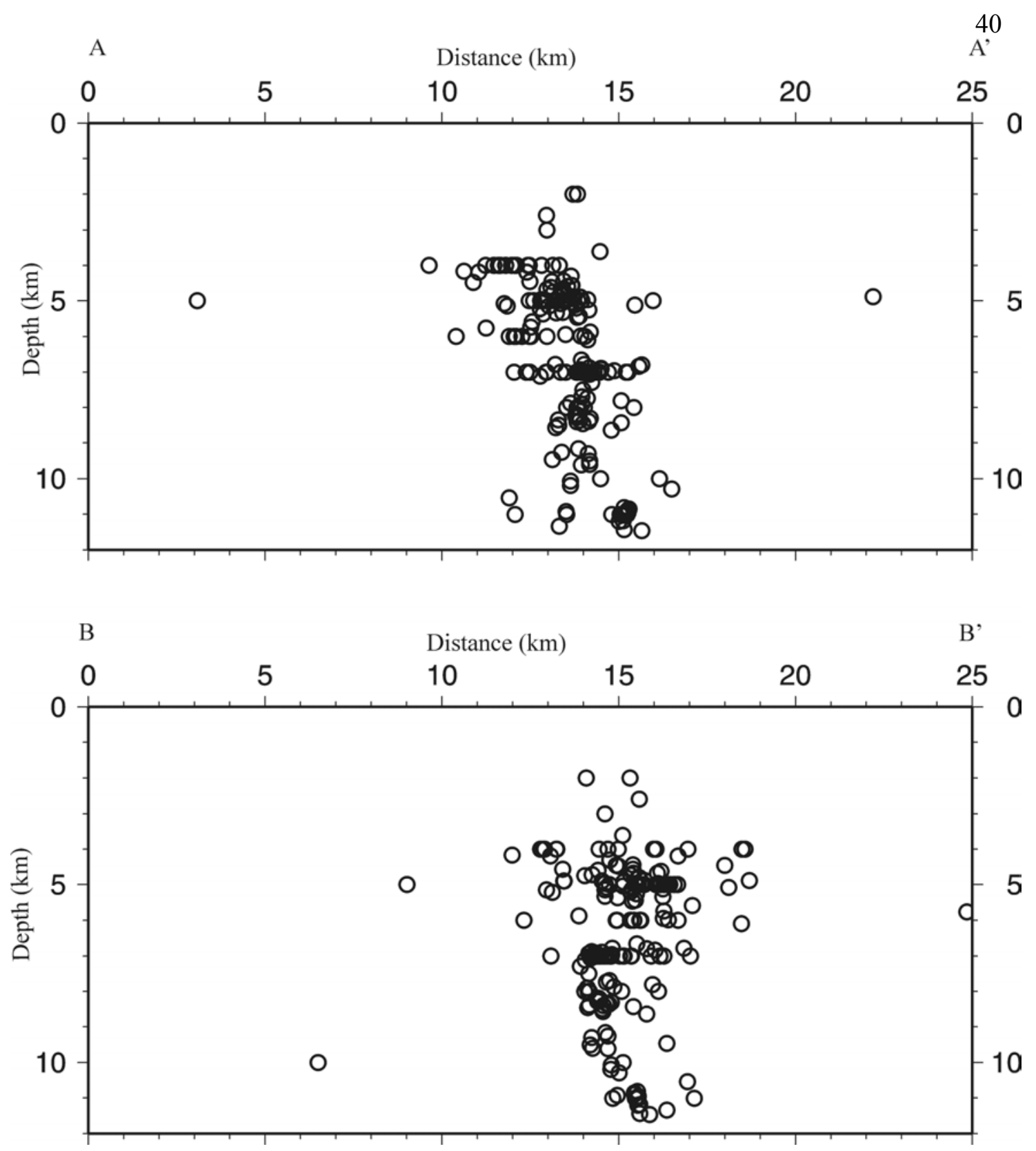

Figure 3.13. Cross sections of earthquake locations using 1-D isotropic case from EQLOC2. Earthquakes are locating deeper than with other location methods. Linear trends at depth are associated with velocity boundaries. 
intervals. This small amount of anisotropy should do little to affect the locations of microearthquakes in the SSGF.

Locations using the full three-dimensional velocity model could not be completed. The author was unable to get the location program to successfully run using the three-dimensional case. Travel-time tables could be built, but caused the location program to crash when locations were attempted. Significant programming effort was put into trying to resolve this problem. The author could not, within time constraints, solve run-time errors in this location method. However, the relation of relocated earthquakes to the seismic station distribution may have made this method a poor choice for obtaining accurate microearthquake locations. This would not have been the case if there were data for events occurring within the spatial coverage of available well logs. Since the earthquakes and most of the raypaths were outside the region covered by wells, it is unlikely that this method would gain much accuracy in the relocation of microearthquakes, unlike the method described below.

\section{Section 3.6 Location of microearthquakes using HypoDD}

Joint hypocenter determinations (JHD) can provide highly accurate relative relocations for earthquakes. The Double Differencing technique, a JHD technique, is based on Geiger's method for locating earthquakes using the differences between the observed and calculated travel time for both P- and S-waves. Double Differencing benefits from the fact that inter-event differences are much smaller than event to station distances and the scale length of velocity heterogeneity. Thus the ray paths from 
earthquakes in a similar source region are almost the same to a given station. The double difference links events and common stations and minimizes the residuals between event pairs using singular value decomposition (SVD) or a conjugate gradient method (LSQR). HypoDD is a FORTRAN program which implements the double differencing technique, which is described in full by Waldhauser and Ellsworth (2000).

The results from the VELEST 1-D inversion for velocity were used to locate the Salton Sea earthquakes using Hypoinverse. Then these locations (Figures 3.14 and 3.15) were used as the starting locations for HypoDD relocation. The velocity model from the 1-D inversion was used as the layered velocity model input for HypoDD.

Station distribution has been shown to have a greater effect on the accuracy of the results of HypoDD than the starting location of hypocenters by Ross et. al. (2001). Unfortunately, station distribution does not provide good azimuthal coverage for this data set. Another limiting factor of this data is that waveform data could not be used. HypoDD has the capability to use the cross-correlation of waveforms to improve centroid locations and quite possibly could increase the accuracy of locations for a data set with poor station distribution. In order to prevent biasing from the few events with waveforms (Figure 3.2), they were not used in the HypoDD analysis.

HypoDD is fairly sensitive to outliers in P- and S-wave arrivals. Outliers were eliminated for delay times larger than the maximum expected delay time for an event pair. This maximum expected delay time is determined from initial locations from Hypoinverse and the P- and S-wave velocity in the focal area with 0.5 s added to the cutoff to account for uncertainties in initial locations. The catalog P- and S-wave data 


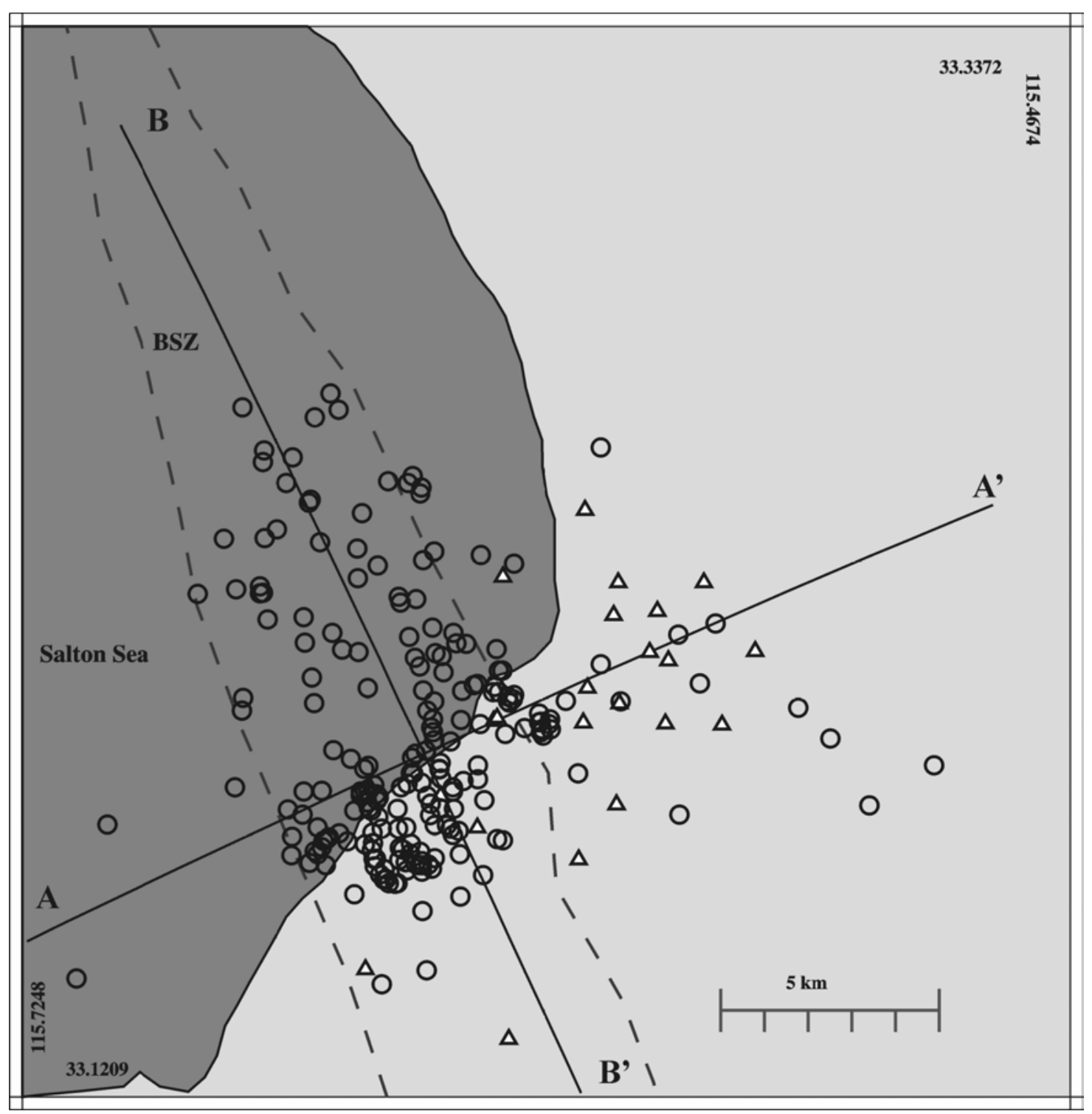

Figure 3.14. Hypocenter locations as determined from Hypoinverse using a velocity model obtained from the 1-D VELEST inversion. Cross sections A to A' and B to B' are shown in Figure 3.15. 

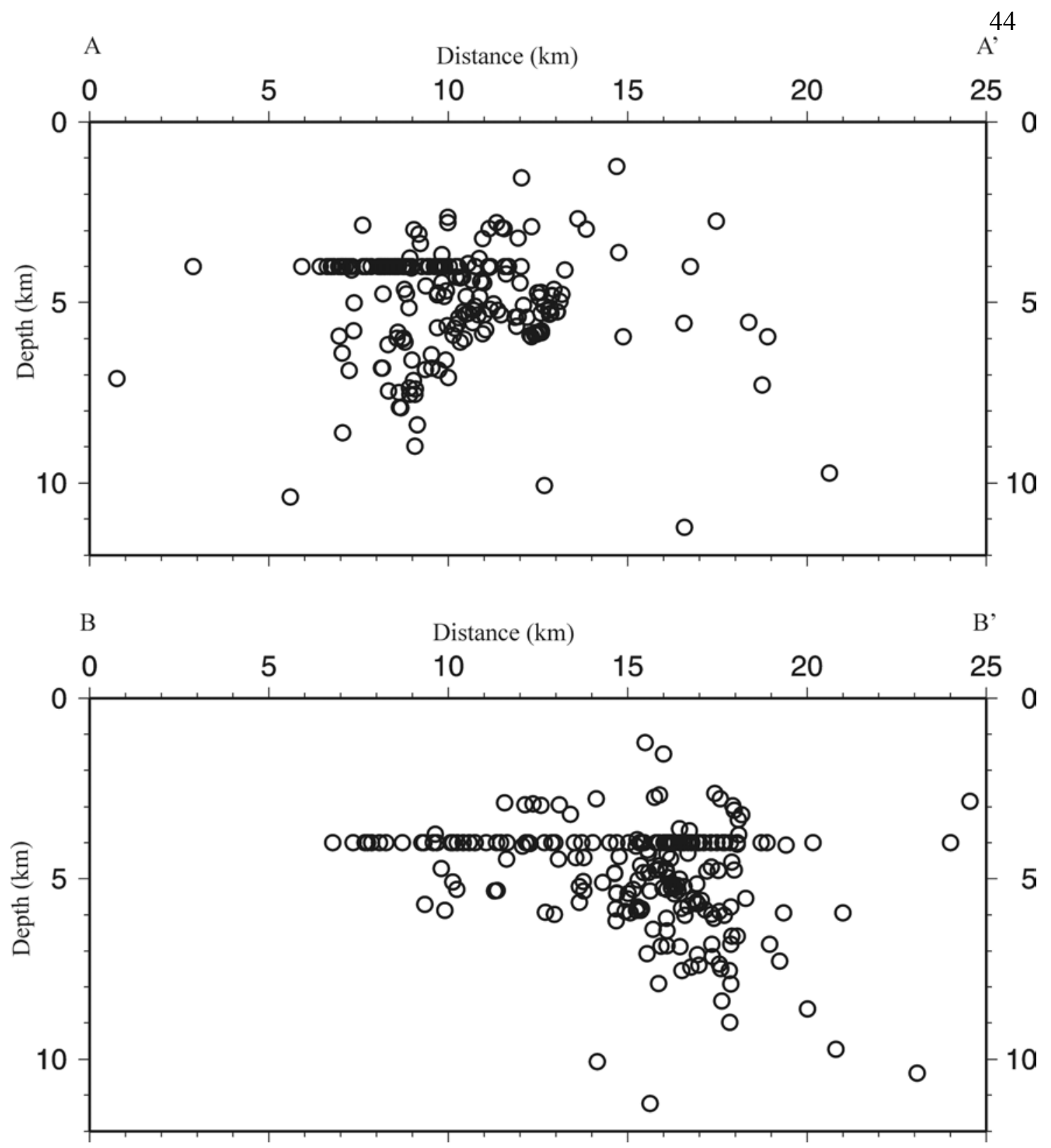

Figure 3.15. Cross sections of hypocenter locations as determined from Hypoinverse using a velocity model obtained from the 1-D VELEST inversion. Concentration of earthquakes at $4 \mathrm{~km}$ depth is due to not enough resolution in earthquake phase arrivals to move hypocenter depths away from initial trial depths. 
were examined for event pairs with phase arrivals at common stations and subsampled in order to increase the connectivity of event pairs and phase quality. The goal is to establish a chain of event pairs, which connect the entire data set with as little inter-event distance as possible. HypoDD groups events into clusters in an attempt to maintain as much connection of events as possible. Events that do not remain connected during relocation get deleted.

Singular Value Decomposition (SVD) was used to minimize the residuals. This method of controlling the convergence behavior of HypoDD produces more accurate estimates of the true error in the relative locations of hypocenters than LSQR (Waldhauser and Ellsworth, 2000). The choice to use SVD did dramatically affect the computation time required by orders of magnitude for the entire data set. Given the station distribution it seemed well worth the trade-off to obtain better estimates of location error. The increased computation time required for SVD required that the program be run in LSQR mode to evaluate a priori weighting and iteration parameters to provide the best connectivity of the data. Once the initial settings that seemed adequate for the LSQR were determined, they were applied to the SVD case. It was found that a maximum interevent separation of $2 \mathrm{~km}$ and a minimum number of event-station links of 3 provided the greatest number of linked events. Any reduction in the interevent distance caused very few events to link. Due to the limited number of stations, increasing the event-station link requirements also caused very few links to occur. The first 5 iterations only weighted the catalog P-wave arrivals. The next 5 iterations included S-wave phase arrivals at half the weight of $\mathrm{P}$-wave arrivals. 
Initial data input into HypoDD was for 201 events, 23 stations, 4151 P-arrivals, and 3626 S-arrivals. On the first iteration 16 events, 1 station, and 20 phase arrivals were dropped from the data set. By the final iteration only 166 events, 17 stations, and 2057 phase arrivals were left in the data set. Final hypocenter locations for these 166 earthquakes are shown in Figures 3.16 and 3.17. Due to the small aperture of the data set, all but 2 events were placed in the same cluster. With a better station distribution it would probably be advantageous to work the association of events into more than one cluster. This change would reduce the number of observations used, which would do more to increase than decrease the uncertainty in locations in this study. The data also show just one major cluster in the southwest portion of the data set, as seen in Figure 3.16, so that attempting to break up the data set may be arbitrary. In cross section (Figure 3.17) there appear to be a few definable structures, however, in viewing the data using the 3-D projection there appears to be enough distance between events that associating them with some structure would be pure conjecture without more earthquakes to fill in the gaps.

\section{Section 3.7 Focal mechanisms and Coulomb failure analysis}

Focal mechanisms for microearthquakes within the SSGF were calculated using the program FPFIT (Reasenberg and Oppenheimer, 1985). Hypoinverse locations were used due to simplicity of input to FPFIT. The locations could not be forced to locations obtained by HypoDD because the locations obtained by Hypoinverse were already quite close generally within $2 \mathrm{~km}$ to those obtained from HypoDD and the method for forcing 


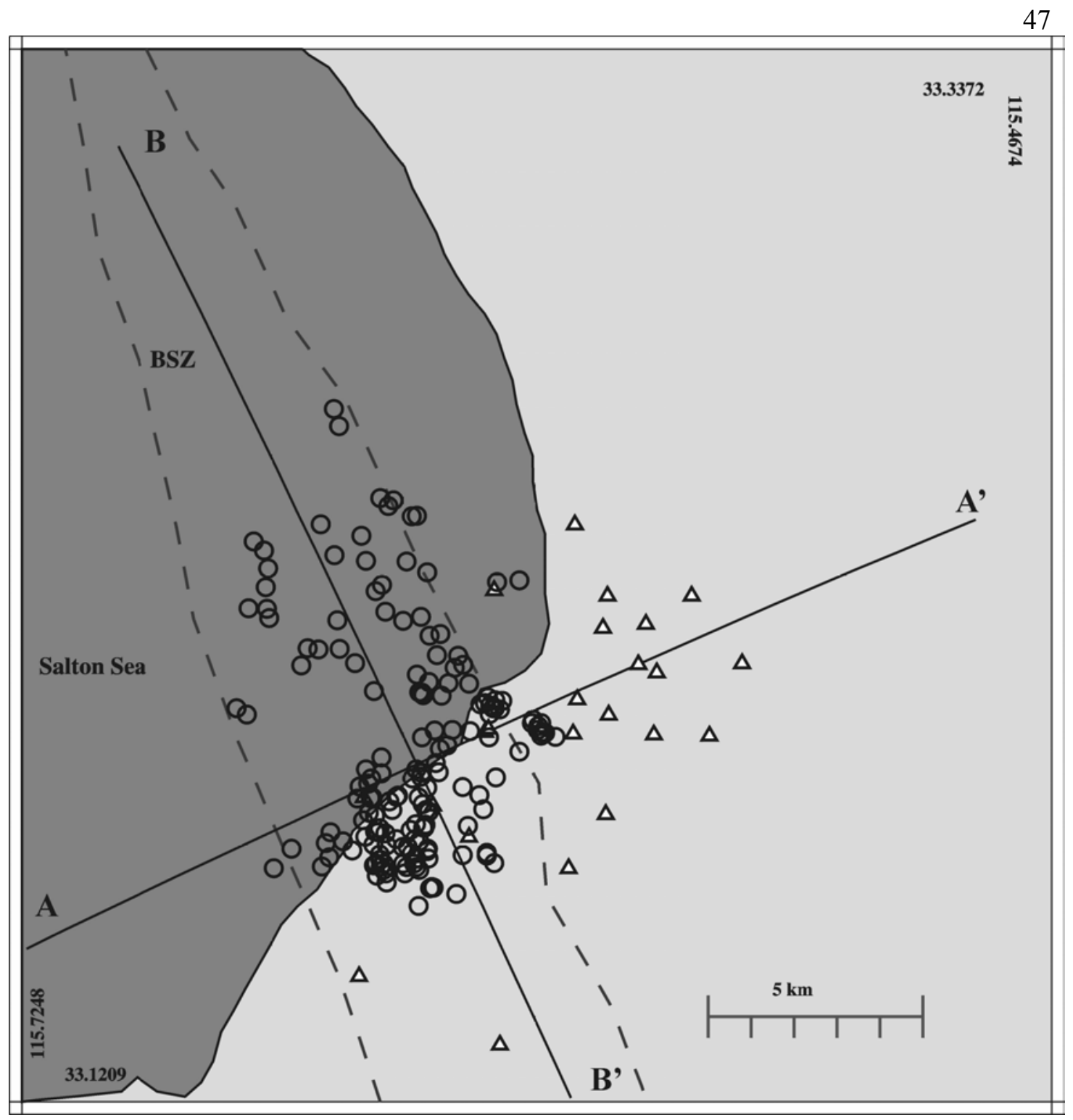

Figure 3.16. Hypocenter locations relocated using hypoDD for a subset of 166 earthquakes from the study period. Cross sections A to A' and B to B' are shown in Figure 3.17. 

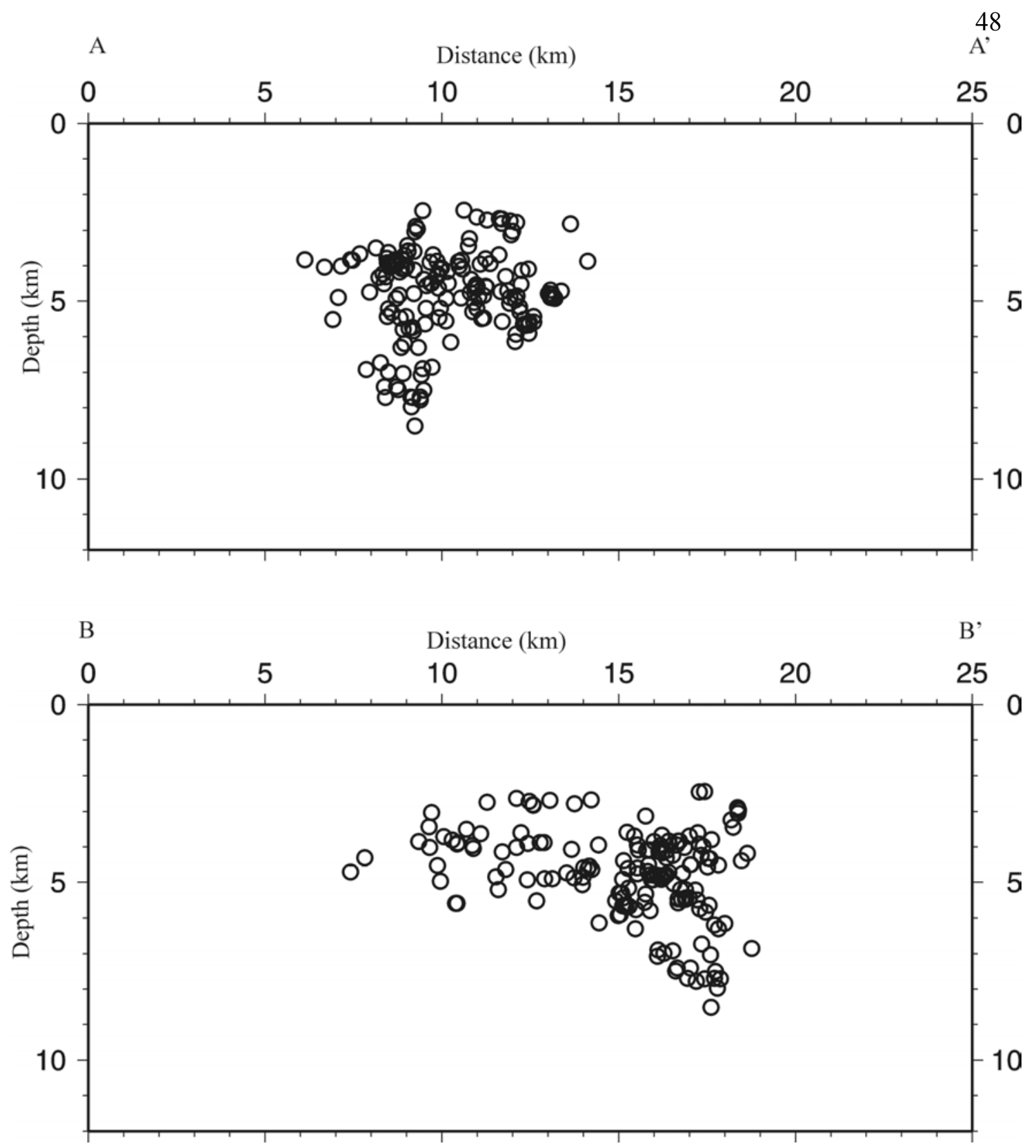

Figure 3.17. Cross sections of hypocenter locations relocated using hypoDD for a subset of 166 earthquakes from the study period. Hypodd moved those initial locations at a depth of $4 \mathrm{~km}$ by comparing similarities to earthquakes with more phase arrival data. 
locations in Hypoinverse to a specific hypocenter does not contain enough accuracy. The focal mechanisms are poorly constrained due to large azimuthal gaps arising from poor station distribution and lack of waveforms. Twenty-one events for which a large number of first motions had been picked were selected from the data set. These focal mechanisms were highly variable and poorly constrained. Composite focal mechanisms for events with above average station distribution were then calculated. These composite focal mechanisms did not improve the results from FPFIT. Due to the limitations of the data set, meaningful focal mechanisms could not be obtained. Instead, a method to invert first motion observations to obtain a stress tensor for microearthquake studies was applied.

Inversion to obtain stress tensor from microearthquake first motion data was done following the method described by Robinson and McGinty (2000). This method applies the Coulomb failure criteria of Okada (1992) to the observations of first motion. This method searches over stress tensor orientations and finds the stress tensor orientation which best matches the observations in the data set. Robinson and McGinty (2000) determined that this method is less dependent on station distribution than focal mechanism methods and can often find principal stress axis when no single well constrained focal mechanism could be obtained. The inversion uses a bootstrap method that samples with replacement to obtain the best stress tensor within a given confidence interval. A 95\% confidence interval was used for this analysis with a fine resolution of the stress tensor of $2^{\circ}$. 
A dry coefficient of friction of 0.7 was used for this analysis. This value is similar to that used by Robinson and McGinty (2000). Many studies of Coulomb failure in southern California such as King et. al. (1994) use a coefficient of friction of 0.4. This inversion was initially run with several different coefficients of friction ranging from 0.4 to 0.75 , however all resulted in roughly the same stress tensor result. The largest effect of changing the coefficient of friction was a variation of about $6^{\circ}$ in the strike or dip of the $\sigma_{1}$ and $\sigma_{3}$ axis of the stress tensor. However, a coefficient of friction of 0.7 provided the greatest number of reproduced first motion observations at $89 \%$.

The stability of the results was tested by varying the random number seed input into the program. This did not affect the resultant stress tensor, indicating that the inversion was converging to a stable solution. One thousand and one first motion observations made up the data set used in this study. There was no change in the resultant stress tensor by including only first motion observations for events with 3 or more observations when compared to using all first motion data.

The data was then divided into two data sets consisting of earthquakes occurring before and after the Superstition Hills Sequence (SHS) of November 24, 1987 (Figures 3.18 and 3.19). There appears to be deepening of earthquakes in the southern cluster of events. There are no earthquakes located at these deeper focal depths before the SHS. These events may be associated with the Elmore Ranch fault. The concentration of earthquakes at $4 \mathrm{~km}$ depth may skew results obtained by affecting reported take off angles. Fortunately, these are events with few phase arrivals. These events often did not have any first motion observations. The results for all the data and the two subsets can be 


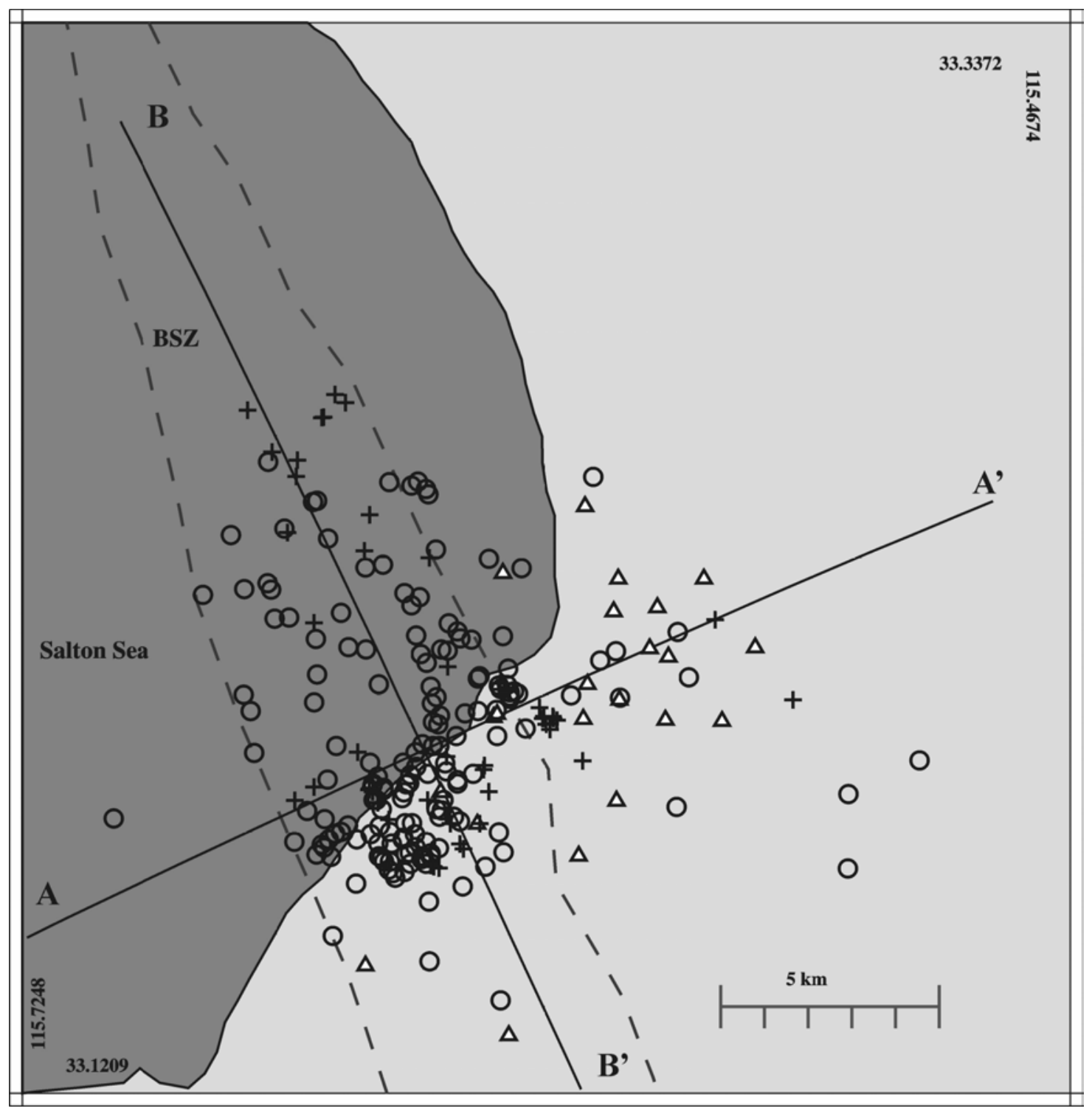

Figure 3. 18. Earthquakes occurring before the SHS (crosses) and after (circles) located by Hypoinverse. Cross sections A to A' and B to B' are shown in Figure 3.17. 

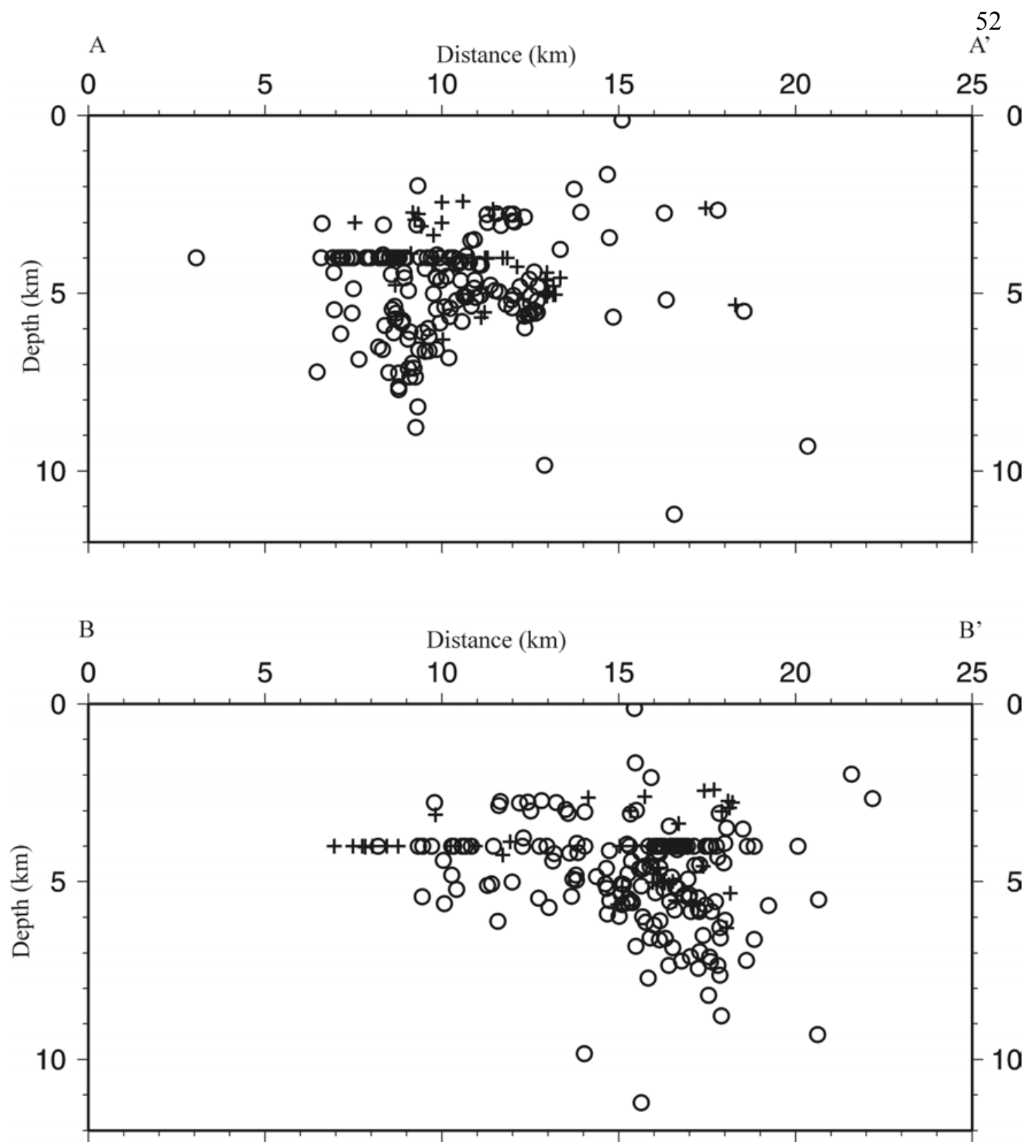

Figure 3.19. Cross sections of earthquakes occurring before the SHS (crosses) and after (circles) located by Hypoinverse. 
seen in Table 3.4. Since the data set of first motion picks for earthquakes occurring before the SHS contained only 278 observations, steps were taken to ensure that the limited number of observations was not affecting the convergence of the resultant stress tensor. This was done by increasing the number of iterations used in the calculation from 1000 to 3000 to make up for the smaller size of the data set and by doubling the observations by adding a copy of the observations to themselves. Neither of these tests provided any changes to the resultant stress tensor, indicating convergence to a stable solution. McGinty et. al. (2000) also saw a rotation of principal stress axis due to large events in New Zealand, indicating that it is not uncommon to see such behavior from this method.

Table 3.4. Stress tensor solutions from inversion of first motion data.

\begin{tabular}{|l|c|c|c|c|c|c|}
\hline \multirow{2}{*}{} & \multicolumn{2}{|l|}{ All First Motions } & Pre-SHS (11/24/87) & \multicolumn{2}{c|}{ Post-SHS (11/24/87) } \\
\cline { 2 - 7 } & strike & dip & strike & dip & strike & dip \\
\hline$\sigma_{1}$ & 200 & 6 & 180 & 10 & 200 & 0 \\
\hline$\sigma_{3}$ & 290 & 0 & 280 & 44.6 & 290 & 10 \\
\hline
\end{tabular}

Stress tensor data indicate that there was a change to the stress state of the SSGF associated with the Superstition Hills Sequence. To examine the effects of the SHS on the SSGF, Coulomb 2.0 (King et. al., 1994 and Toda et. al., 1998) was used to calculate the static stress changes associated with rupture of the Elmore Ranch and Superstition Hills Fault on November, 24, 1987. This method also applies the Coulomb failure criteria to assess effects of fault rupture in a homogenous half space. For this analysis, I assumed a regional stress field with a $\sigma 1$ of $189^{\circ}$ and a $\sigma 3$ of $279^{\circ}$ (Zoback and Zoback, 1980), based on historic earthquake focal mechanisms. This compares well to the values 
used by King et. al. (1994) for other parts of southern California, which they claimed had little effect on the static stress changes associated with significant earthquake rupture. King et. al. (1994) found that a coefficient of friction of 0.4 was most appropriate for southern California and that is the value used for this part of the study.

Rupture parameters for the Elmore Ranch and Superstition Hills faults were taken from Larsen et. al. (1992). These rupture parameters were used because they are the most detailed available for both the Elmore Ranch and Superstition Hills Rupture. Due to the complex rupture of the Superstition Hills event there is a lot of data for the details of rupture along the fault. However, to maintain consistency between the two events, GPS modeling of displacement by Larsen et. al. (1992) provided the input fault model. The moment release reported for the two earthquakes by Larsen et. al. (1992) compare well to those obtained by Sipkin (1989) and Bent et. al. (1989). However, moment release calculated for the modeled rupture process from the inversion of strong motion data suggested a smaller moment release for the Superstition Hills fault (Wald et. al., 1990; Frankel and Wennerberg, 1989).

Figure 3.20 shows the static coulomb stress changes associated with the SHS at a target depth of $4 \mathrm{~km}$ corresponding to the center of the microearthquake zone observed in this study. Earthquakes occurring after the SHS are mostly located within regions of increased Coulomb stress associated with the November 1987 events. King et. al.(1994) indicate that stress increases of greater than 0.1 bars can often initiate stress triggering. Most of the events shown in Figure 3.20 lie in a region with coulomb stress changes greater than 1 bar. 

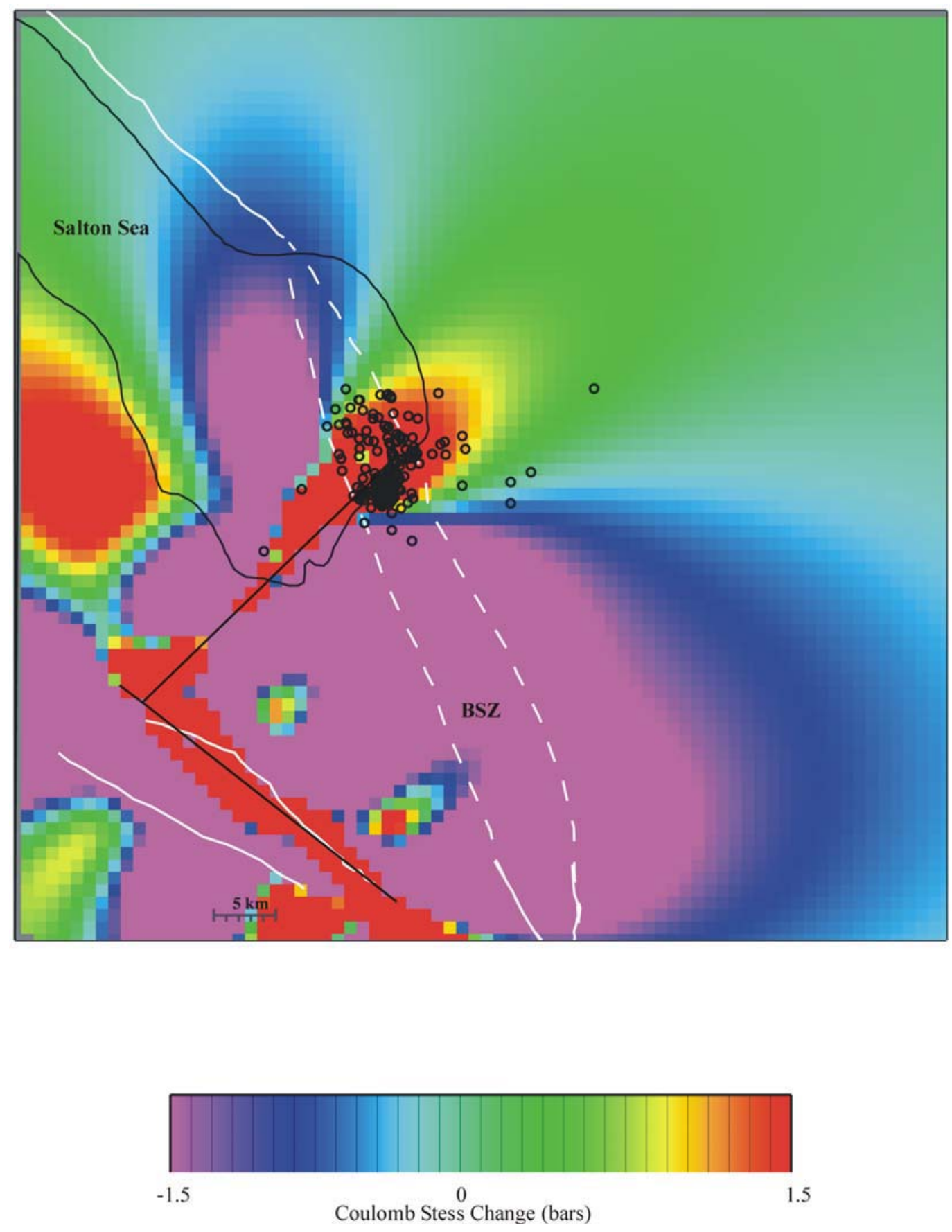

Figure 3.20. Coulomb stress change for optimally oriented faults, at $4 \mathrm{~km}$ depth, associated with rupture on the Elmore Ranch and Superstition Hills faults on November 24, 1987. Solid black lines indicate location of rupture for the Elmore Ranch and Superstition Hills earthquakes from modeling of GPS measurements (Larsen et. al., 1992). Open circles indicate location of earthquakes occurring after the Superstition Hills Sequence. 
Coulomb analysis indicates that the principal stress axis where earthquakes were occurring after the SHS to be $\sigma_{1}$ of $192^{\circ}$ strike $2^{\circ}$ dip and a $\sigma_{3}$ of $281^{\circ}$ strike and $7^{\circ}$ dip. This compares reasonably well to the results obtained from first motions inverted for stress field after the SHS given the difference in methods. 


\section{Chapter 4}

\section{DISCUSSION}

The primary goal of this study was to obtain highly accurate microearthquake locations for earthquakes occurring near the Salton Sea Geothermal Field (SSGF) in order to image deep fracture systems. Several methods were used to locate earthquakes within the SSGF. Location statistics are given in Table 4.1 for all methods except the VELEST 1-D inversion. All location methods were hindered by the limitations of the data set mentioned at the beginning of Chapter 2 .

Table 4.1. Statistics for location methods applied in this study. HypoDD reports location errors for all three primary axis in meters. Hypoinverse and EQLOC2 report the largest horizontal error and the vertical error in kilometers.

\begin{tabular}{|c|c|c|c|c|}
\hline & \multicolumn{4}{|c|}{ HypoDD } \\
\hline & error $\mathrm{x}(\mathrm{m})$ & error y $(\mathrm{m})$ & error $z(m)$ & RMS residual (s) \\
\hline Mean & 118.9 & 96.5 & 100.5 & 0.017 \\
\hline Standard Deviation & 74.6 & 56.3 & 58.6 & 0.008 \\
\hline
\end{tabular}

\begin{tabular}{|l|r|r|r|}
\hline & \multicolumn{3}{|c|}{ Hypoinverse } \\
\hline & horizontal error $(\mathrm{km})$ & vertical error $(\mathrm{km})$ & RMS residual $(\mathrm{s})$ \\
\hline Mean & 2.0 & 6.0 & 0.077 \\
\hline Standard Deviation & 7.0 & 7.7 & 0.268 \\
\hline
\end{tabular}

\begin{tabular}{|l|r|r|r|}
\hline & \multicolumn{3}{|c|}{ EQLOC2 } \\
\hline & horizontal error (km) & vertical error (km) & RMS residual (s) \\
\hline Mean & 0.91 & 0.87 & 0.553 \\
\hline Standard Deviation & 0.19 & 0.24 & 0.327 \\
\hline
\end{tabular}


Hypoinverse locations (Figures 3.14 and 3.15) had the largest average errors with an average horizontal error of $2.0 \mathrm{~km}$ and an average vertical error of $6 \mathrm{~km}$. Hypoinverse located a large number of earthquakes at $4 \mathrm{~km}$ depth. This is the trial depth where Hypoinverse starts the location process. If the phase data are insufficient to move the location away from the initial trial depth, Hypoinverse will often report high vertical errors. The smallest location errors reported for horizontal and vertical errors were on the order of $100 \mathrm{~m}$ for the best-located events. However, Hypoinverse did report an average RMS of 0.077 seconds, which is quite good. The low average RMS is due in part because Hypoinverse attempts to minimize travel time residuals in the location process.

The assessment of anisotropy observed in well logs at the SSGF indicates that significant anisotropy most likely exists. Unfortunately, the observed anisotropy could not be incorporated into a location method that accounted for this anisotropy. Anisotropy estimates exhibit a wide range of values with just a few percent in well I.I.D. 2 to up to $40 \%$ in well River Ranch 1. No spatial pattern could be observed in the results of anisotropy estimates.

The method of Nelson and Vidale (1990) modified to the method of Lecomte (1993) for anisotropic media could not be successfully completed in the threedimensional anisotropic case. Locations using EQLOC2 could be obtained in the 1-D isotropic case (Figures 3.13 and 3.14). Locations for earthquakes using this method were pushed to the center of the seismograph network and deeper focal depths were obtained compared to other methods. These deeper depths are suspect considering the 
work of Gilpin and Lee (1978) that observed the most seismicity between 0.5 and 3.5 $\mathrm{km}$ depth. High heat flow in the area would also suggest that the deep focal depths might be in error. This method had a tendency to group events together at depths corresponding to velocity model boundaries. EQLOC2 reported much smaller average horizontal $(0.91 \mathrm{~km})$ and vertical errors $(0.87 \mathrm{~km})$ than Hypoinverse. However, EQLOC2 had a very high average RMS of 0.553 seconds. This location method also tries to minimize travel time residuals indicating something was not quite correct in this location algorithm or parameter setup. The author worked to resolve these issues but could not alter this behavior.

Travel time tables built using an anisotropic 3-D velocity model could not be correctly read by EQLOC2 and the program continually crashed during the location process with garbled results. This indicates that the travel-time tables were not getting read or built correctly. Significant effort was placed into resolving this issue, but to no avail. This method could perhaps provide accurate locations for microearthquakes with a well-designed data set. However, most microearthquakes occurred outside the network of wells used to estimate the anisotropy, so the anisotropy estimates may not be valid for the microearthquake source region. Sonic logs provide the most reliable estimate of seismic anisotropy. A lack of sonic logs required using induction logs as a proxy. This introduces significant error into the method, especially in a saturated environment. Sonic tools designed to assess seismic anisotropy that are now readily available may be the best means for obtaining data in the future for use with this method. This method does have the potential to be applied to locating earthquakes in an 
area where a tomographic inversion for anisotropy parameters has already determined the anisotropic parameters of the study area, similar to the one conducted at the Coso geothermal field, California by Lees and Wu (1999).

Microearthquake locations using the joint hypocenter determination method of Double-Differencing (Waldhauser and Ellsworth, 2000) incorporated in the HypoDD program did improve earthquake locations (Figures 3.16 and 3.17). Notice that average errors for HypoDD locations are much less than for any other method. This occurs, in part, because HypoDD removes phase arrival and location outliers from the data set. HypoDD takes locations reported by Hypoinverse as its starting point. HypoDD was able to move focal depths away from the $4 \mathrm{~km}$ trial depth. These events more often than not were relocated with focal depths ranging between 3 and $5 \mathrm{~km}$ depth. Average RMS residuals were 0.06 seconds less than those obtained by Hypoinverse. Average location errors reported by HypoDD in all directions were on the order of $100 \mathrm{~m}$, the sort of resolution needed to image structures at depth. Cross-sections (Figure 3.17) indicate that a few potential structures may exist. Most notably are two parallel structures observable in the B to B' cross section below $5.5 \mathrm{~km}$ depth dipping about $50^{\circ}$ to the southeast.

Waveform cross correlation has been shown by Waldhauser and Ellsworth (2000) to significantly improve earthquake locations using this method. Had this portion of the technique been utilized perhaps more potential structures could have been imaged. The HypoDD method was added to the study well after work was underway and more rigorous analysis could possibly further refine locations. More work would 
need to be done to assess whether or not the observed structures are an artifact of the location algorithm and whether or not earthquake locations are truly defining structures at depth. This location method shows potential to define structures at depth on this data set or others in active or potential geothermal fields.

Inversion of first motions for the stress tensor indicate that rotation of the regional stress field at the SSGF occurred due to Coulomb stress changes associated with the November 24, 1987 Superstition Hills Sequence (SHS). Before the SHS the regional stress field determined from inversion of first motions indicate a more extensional stress regime (Table 3.4). After the SHS the stress field rotated to a strike slip stress regime more in line with regional stress and ruptures on the Superstition Hills and Elmore Ranch faults. This might also reflect stress field change with depth. There appear to be more earthquakes with focal depths greater than $5 \mathrm{~km}$ after the SHS (Figure 3.19). This increase in deep earthquakes may have been in direct response to the SHS or an artifact of the much longer sampling period after the SHS. The stress rotation indicates that the SSGF and surrounding area is highly fractured and that once there was a rotation of the stress field pre-existing optimally oriented fractures became active. Coulomb failure analysis predicted optimal orientations of the stress field that are in close agreement with those determined from first motion data. The predicted orientation of stress axis after the SHS is a $\sigma 1$ of $192^{\circ}$ strike and $2^{\circ}$ dip and a $\sigma 3$ of $281^{\circ}$ strike and $7^{\circ}$ dip from Coulomb analysis. This compares well to the observed $\sigma 1$ of $200^{\circ}$ strike and $0^{\circ}$ dip and a $\sigma 3$ of $290^{\circ}$ strike and $10^{\circ}$ dip from inversion of first 
motions. Earthquakes occurring near the SSGF after the SHS are mostly located within the region of stress increase (Figure 3.20) from Coulomb analysis.

Of the location methods applied in this study the Double-Differencing technique provided the most accurate locations. Hypocenter locations suggest a few possible structures may exist within the study area. Further analysis using this technique would be required to determine if these structures truly exist or not. This technique yielded location errors on the order of $100 \mathrm{~m}$, which is the resolution required to confidently image fracture systems at depth. HypoDD appears to have potential to image fracture systems at active or potential geothermal fields. Designing a network with good azimuthal coverage of microearthquake sources and a high signal to noise ratio would be key to any future studies of this kind. Also, anisotropy estimates for wells indicate that anisotropy within the geothermal field is significant enough to affect microearthquake locations, and should be included to obtain accurate locations in future studies. The Superstition Hills Sequence caused a rotation of the principal stress axis within the study area. The results from Coulomb analysis indicate that stress triggering did occur at the Salton Sea Geothermal Field in response to the Superstition Hills Sequence of November 24, 1987. 


\section{REFERENCES}

Bent, A.L., Helmberger, D.V., Stead, R.J., Ho-Lui, P., Waveform modeling of the November 1987 Superstition Hills earthquakes, Bulletin of the Seismological Society of America, Vol. 79, No. 2, pp. 500-514, 1989.

Daley, T.M., McEvilly, T.V., Majer, E.L., Analysis of P and S Wave Vertical SeismicProfile Data From the Salton Sea Scientific Drilling Project, Journal of Geophysical Research, Vol. 93, No. B11, pp. 13,025-13,036, 1988.

Elders, W.A., Sass, J.H., The Salton Sea Scientific Drilling Project, Journal of Geophysical Research, Vol. 93, No. B11, pp. 122,953-12,968, 1988.

Evans, J.R., Eberhart-Phillips, D., Thurber, C.H., User's Manual for SIMULPS12 forImaging $v_{p}$ and $v_{p} / v_{s}$ : A derivative of the "Thurber" tomographic inversion SIMUL3 for local earthquakes and explosions, USGS Open File Report 94-431, 1994.

Frankel, A. and Wennerberg, L., Rupture process of the Ms 6.6 Superstition Hills, California, earthquake determined from strong-motion recordings: application of tomographic source inversion, Bulletin of the Seismological Society of America, Vol. 79, No. 2, pp. 515-541, 1989.

Fuis, G.S., Mooney, W.D., Healy, J.H., McMechan, G.A., Lutter, W.J., Crustal Structure of the Imperial Valley, in The Imperial Valley, California, Earthquake of October15, 1979, USGS Professional Paper 1254, pp. 15-24, 1982.

Gilpin, B., Lee, T-C, A Microearthquake Study in the Salton Sea Geothermal Area, California, Bulletin of the Seismological Society of America, Vol. 68 No. 2, pp. 441-450, 1978.

Helgeson, H.C., Geologic and Thermodynamic Characteristics of the Salton Sea Geothermal System, American Journal of Science, Vol. 266, pp. 129-166, 1968.

Herzig, C.T. and Elders, W.A., Nature and significance of igneous rocks cored in the State 2-14 research borehole: Salton Sea Scientific Drilling Project, California, Journal of Geophysical Research, Vol. 93, No. B11, pp. 13069-13080, 1988.

Herzig, C.T. and Mehegan, J.M., Lithostratigraphy of the State 2-14 borehole: Salton Sea Scientific Drilling Project, Journal of Geophysical Research, Vol. 93, No. B11, pp. 12969-12980, 1988.

Hill, R., The Elastic Behaviour of a Crystalline Aggregate, Proceedings of the PhysicalSociety of London, A, 65, pp. 349-354, 1952. 
Hudnut, K., Seeber, L., Rockwell, T., Goodmacher, J., Klinger, R., Lindvall, S., McElwan, R., Surface ruptures on cross-faults in the 24 November 1987 Superstition Hills, California, earthquake sequence, Bulletin of the Seismological Society of America, Vol. 79 No. 2, pp. 282-296, 1989a.

Hudnut, K.W., Seeber, L., Rockwell, T., Slip on the Elmore Ranch fault during the past 330 years and its relation to slip on the Superstition Hills, Bulletin of the Seismological Society of America, Vol. 79 No. 2, pp. 330-341, 1989b.

Hudnut, K.W., Sieh, K.E., Behavior of the Superstition Hills fault during the past 330 years, Bulletin of the Seismological Society of America, Vol. 79 No. 2, pp. 304-329, 1989.

Johnson, C.E., Hadley, D.M., Tectonic Implications of the Brawley Earthquake Swarm, Imperial Valley, California, January 1975, Bulletin of the Seismological Society of America, Vol. 66 No. 4, pp. 1133-1144, 1976.

Johnson, C.E., Hill, D.P., Seismicity of the Imperial Valley, in The Imperial Valley, California, Earthquake of October15, 1979, USGS Professional Paper 1254, pp. 15-24, 1982.

Jost, M.L., BuBelberg, O., Jost, O., Harjes, H.P., Source Parameters of Injection Induced Microearthquakes at $9 \mathrm{~km}$ Depth at the KTB Deep Drilling Site, Germany, Bulletin of the Seismological Society of America, Vol. 88 No. 3, pp. 815-832, 1998.

Karnassopoulou, A., Pearce, R.G., Booth, D.C., A Method to Determine Microearthquake Focal Mechanisms in the Presence of Seismic Anisotropy, Tectonophysics, 261, pp. 115-126, 1996.

Kasameyer, P.W., Hearst, J.R., Borehole Gravity Measurements in the Salton Sea Scientific Drilling Project Well State 2-14, Journal of Geophysical Research, Vol. 93, No. B11, pp. 13,037-13,045, 1988.

King, G.C., Stein, R.S., Lin, J., Static stress changes and the triggering of earthquakes, Bulletin of the Seismological Society of America, Vol. 84 No. 3, pp. 935-953, 1994.

Kissling, E., Ellsworth, W.A., Eberhart-Phillips, D., Kradolfer, U., Initial reference model in local earthquake tomography, Journal of Geophysical Research, Vol. 99, No. B10, pp. 19,635-19,646, 1994.

Klein, F.W., User's Guide to HYPOINVERSE-2000 a Fortran Program to Solve for Earthquake Locations and Magnitudes, USGS Open File Report, Draft 5/19/2000.

Larsen, S., Reilinger, R., Nuegebauer, H., Strange, W., Global Positioning System measurements of deformations associated with the 1987 Superstition Hills earthquake: evidence for conjugate faulting, Journal of Geophysical Research, Vol. 97, No. B4, pp. 4885-4902, 1992.

Lecomte, I., Finite Difference Calculation of First Traveltimes in Anisotropic Media, Geophysical Journal International, pp. 318-342, 1993. 
Lees, J.M. and Wu, H., P wave anisotropy, stress, and crack distribution at Coso gerothermal field, California, Journal of Geophysical Research, Vol. 104, No. B8, pp. 17985-17973, 1999.

Lofgren, B.E., Measured Crustal Deformation in Imperial Valley, California, USGS Open-File Report 78-910, 1978.

Magistrale, H., Jones, L., Kanamori, H., The Superstition Hills Earthquakes of 24 November 1987, Bulletin of the Seismological Society of America, Vol. 79 No. 2, pp. 239-251, 1989.

McGill, S.F., Allen, C.R., Hudnut, K.W., Johnson, D.C., Miller, W.F., Sieh, K.E., Slip on the Superstition Hills fault and on nearby faults associated with the 24 November 1987 Elmore Ranch and Superstition Hills earthquakes, southern California, Bulletin of the Seismological Society of America, Vol. 79 No. 2, pp. 362-375, 1989.

McGinty, P., Reyners, M., Robinson, R., Stress directions in the shallow part of the Hikurangi subduction zone, New Zealand, from the inversion of earthquake first motions, Geophysical Journal International, Vol. 142, No. 2, pp. 339-350, 2000.

Nelson, G.D., Vidale, J.E., Earthquake Locations by 3-D Finite-Difference Travel Times, Bulletin of the Seismological Society of America, Vol. 80 No. 2, pp. 395-410, 1990.

Newmark, R.L., Kasameyer, P.W., Younker, L.W., Shollow Drilling in the Salton Sea Region: The Thermal Anomaly, Journal of Geophysical Research, Vol. 93, No. B11, pp. 13005-13023, 1988.

Okada, Y., Internal Deformation Due to Shear and Tensile Faults in a HalfSpace, Bulletin of the Seismological Society of America, Vol. 82, pp. 1017-1040, 1992.

Paillet, F.L., Morin, R.H., Analysis of Geophysical Well Logs Obtained in the State 2-14 Borehole, Salton Sea Geothermal Area, California, Journal of Geophysical Research, Vol. 93, No. B11, pp. 12,981-12,994, 1988.

Reasenberg, P.A. and Oppenheimer, D., FPFIT, FPPLOT, FPPAGE: Fortran computer programs for calculating and displaying earthquake fault-plane solutions, USGS Open File Report No. 85-739, 1985.

Robinson, R., McGinty, P.J., The enigma of the Arthur's Pass, New Zealand, earthquake 2. The aftershock distribution and its relation to regional and induced stress fields, Journal of Geophysical Research, Vol. 105, No. B7, pp. 16,139$16,150,2000$.

Romero, A.E., Kirkpatrick, A., Majer, E.L., and Peterson, J.E., Seismic Monitoring at the Geysers Geothermal Field, Geothermal Resources Council Transactions, Vol. 18, October 1994.

Romero, A.E., McEvilly, T.V., Majer, E.L., 3-D Microearthquake attenuation tomography at the Northwest Geysers geothermal region, California, Geophysics, Vol. 62 No. 1, pp. 149-167, 1997. 
Ross, S.L., Michael, A.J., Ellsworth, W.L., Julian, B., Klein, F., Oppenheimer, D., Richards-Dinger, K., Waldhauser, F., Ldeo, Effects of Initial Location Error and Station Distribution on Double-difference Earthquake Relocations: Comparing the San Gregorio and Calaveras Faults, Swismological Research Letters, Vol. 72, No. 2, pp. 291-292, 2001.

Sass, J.H., Priest, S.S., Duda, L.E., Carson, C.C., Hendricks, J.D., Robinson, L.C., Thermal Regime of the State 2-14 Well, Salton Sea Scientific Drilling Project, Journal of Geophysical Research, Vol. 93, No. B11, pp. 12995-13004, 1988.

Scherbaum, F., Combined Inversion for the Three Dimensional Q Structure and Source Parameters Using Microearthquake Spectra, Journal of Geophysical Research, Vol. 95, No.B8, pp.12,423-12,438, 1990.

Sharp, R.V., Tectonic Setting of the Imperial Valley Region, in The Imperial Valley, California, Earthquake of October15, 1979, USGS Professional Paper 1254, pp. 15-24, 1982.

Sipkin, S.A., Moment-tensor solutions for the 24 November 1987 Superstiton Hills, California, earthquakes, Bulletin of the Seismological Society of America, Vol. 79, No. 2, pp. 493-499, 1989.

Tarif, P.A., Wilkens, R.H., Cheng, C.H., Laboratory Studies of the Acoustic Properties of Samples From Salton Sea Scientific Drilling Project and Their Relation to Microstructure and Field Measurements, Journal of Geophysical Reasearch, Vol. 93, No. B11, pp. 13, 057-13,067, 1988.

Toda, S., Stein, R.S., Reasenberg, P.A., Dieterich, J.H., Stress transferred by the $\mathrm{M}_{\mathrm{w}}=6.5$ Kobe, Japan, shock: Efect on aftershocks and future earthquake probabilities, Journal of Geophysical Research, Vol. 103, pp. 524-543, 1998.

Wald, D.J., Helmeberger, D.V.,, Hartzell, S.H., Rupture process of the 1987 Superstition Hills earthquake from the inversion of strong-motion data, Bulletin of the Seismological Society of America, Vol. 80, No. 5, pp. 1079-1098, 1990.

Waldhauser, F., Ellsworth, W.L., A Double-Difference Earthquake Location Algorithm: Method and Application to the Northern Hayward Fault, California, Bulletin of the Seismological Society of America, Vol. 90 No. 6, pp. 1353-1368, 2000.

Younker, L.W., Kasameyer, P.W., Tewhey, J.D., Geological, Geophysical, and Thermal Characteristics of the Salton Sea Geothermal Field, California, Journal of Volcanology and Geothermal Research, 12; pp. 221-258, 1982.

Zoback, M.L. and Zoback, M., State of Stess in the Conterminous United States, Journal of Geophysical Research, Vol. 85, No. B11, pp. 6113-6156, 1980. 


\section{LIST OF SYMBOLS USED}

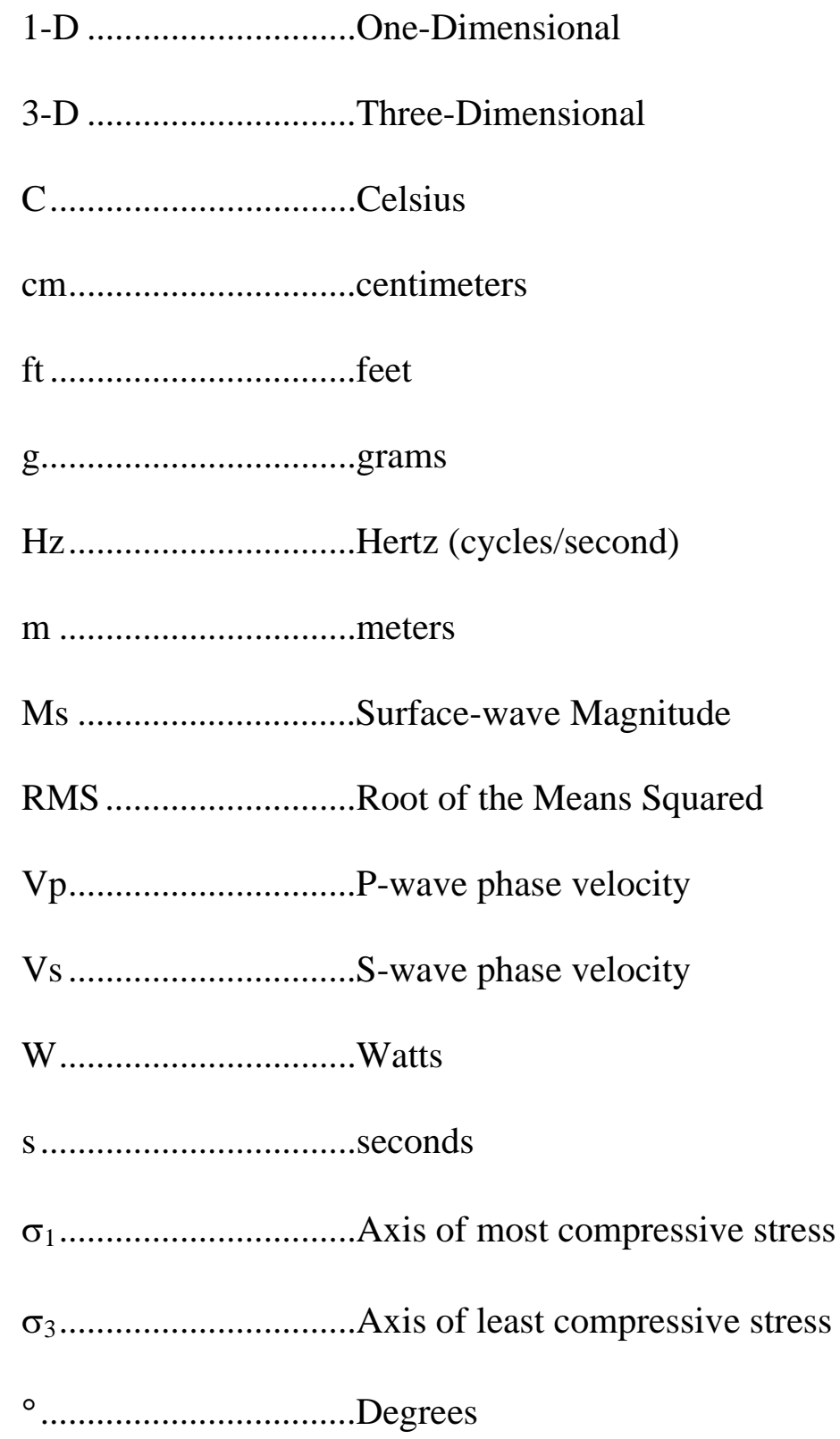


Appendix A 


\section{DESCRIPTION OF WELL LOGS FROM THE SALTON SEA GEOTHERMAL FIELD}

Well logs obtained by the author from the Salton Sea Geothermal Field were digitized at a $0.5 \mathrm{ft}$ spacing. Wells with sonic or induction logs were used in this study. Wells without either of these logs were I.I.D. 1 and Sportsman 1 and were not used, but were shown in Figure 3.7 for reference. Nearly all wells had SP and resistivity (AM 16") logs. Deep induction logs from conductivity (6FF40) and short normal (AM 16") were used to calculate pseudo-transit time curves. Original induction data for wells is not shown unless sonic logs were also recorded at that well. Since pseudo-transit time logs are converted through a common relationship the pseudo-transit time data simply mirror the induction data.

Conventions used in the presentation of well log data are as follows. Red is actual sonic log transit time data. Blue corresponds to the short normal induction log data. Green corresponds to conductivity deep induction log data. Pseudo-transit time data are presented in the color for the type of log they were derived from. Well intervals boundaries for anisotropy estimates are shown as a solid black horizontal lines. 


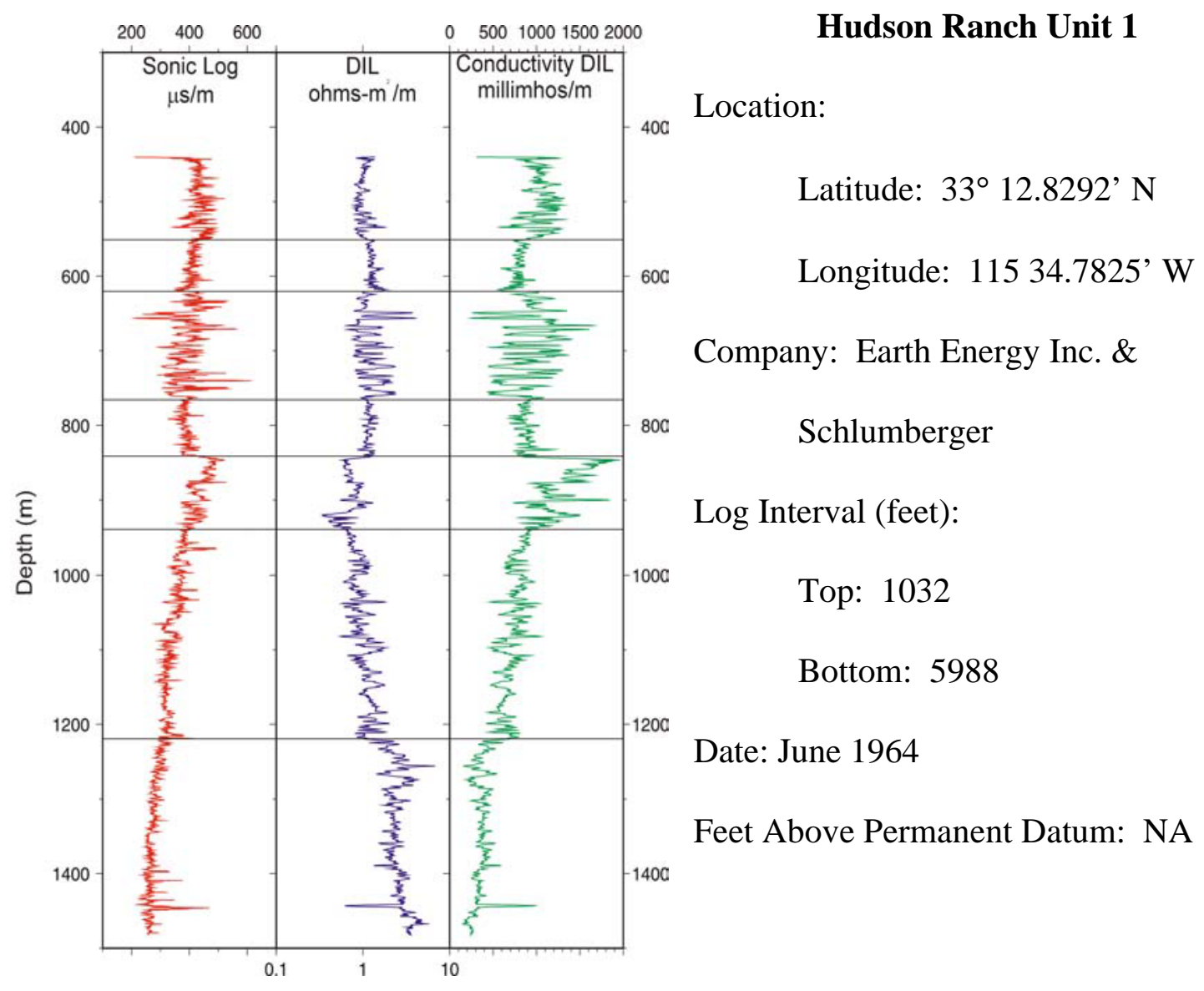




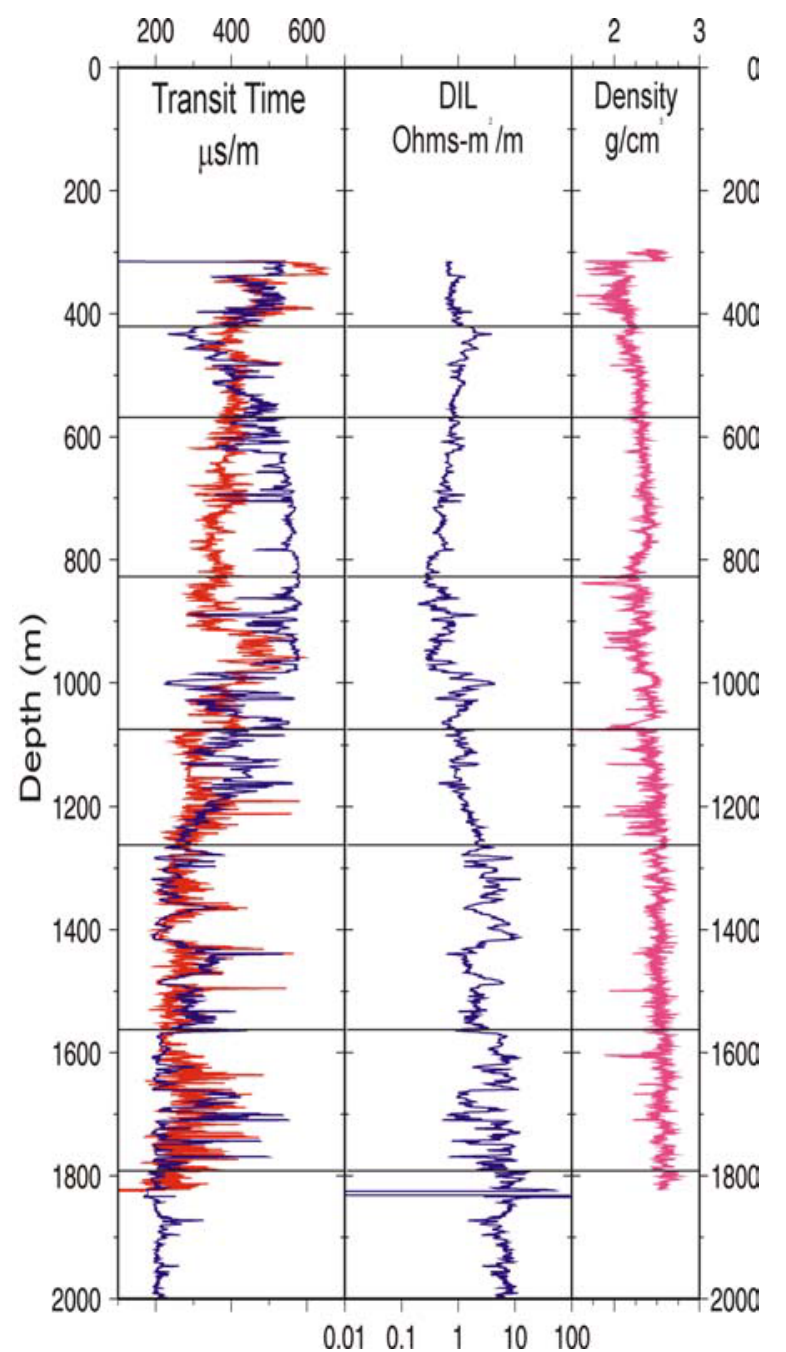

California State 2-14

Location:

Latitude: $33^{\circ} 12.5087^{\prime} \mathrm{N}$

Longitude: $11534.05^{\prime} \mathrm{W}$

Company: Bechtel Corporation \&

Schlumberger

Log Interval (feet):

Top: 1032

Bottom: 5988

Date: June 1964

Feet Above Permanent Datum: 28.7

A deep induction log was run to a well

depth of $8806 \mathrm{ft}$ in March 1986.

Other logs were also run at this

well, but were not used in this study. The total well depth for this well was 10,892 ft and was the well drilled for the Salton Sea Deep Drilling Project as described by Elders and Sass (1988). 


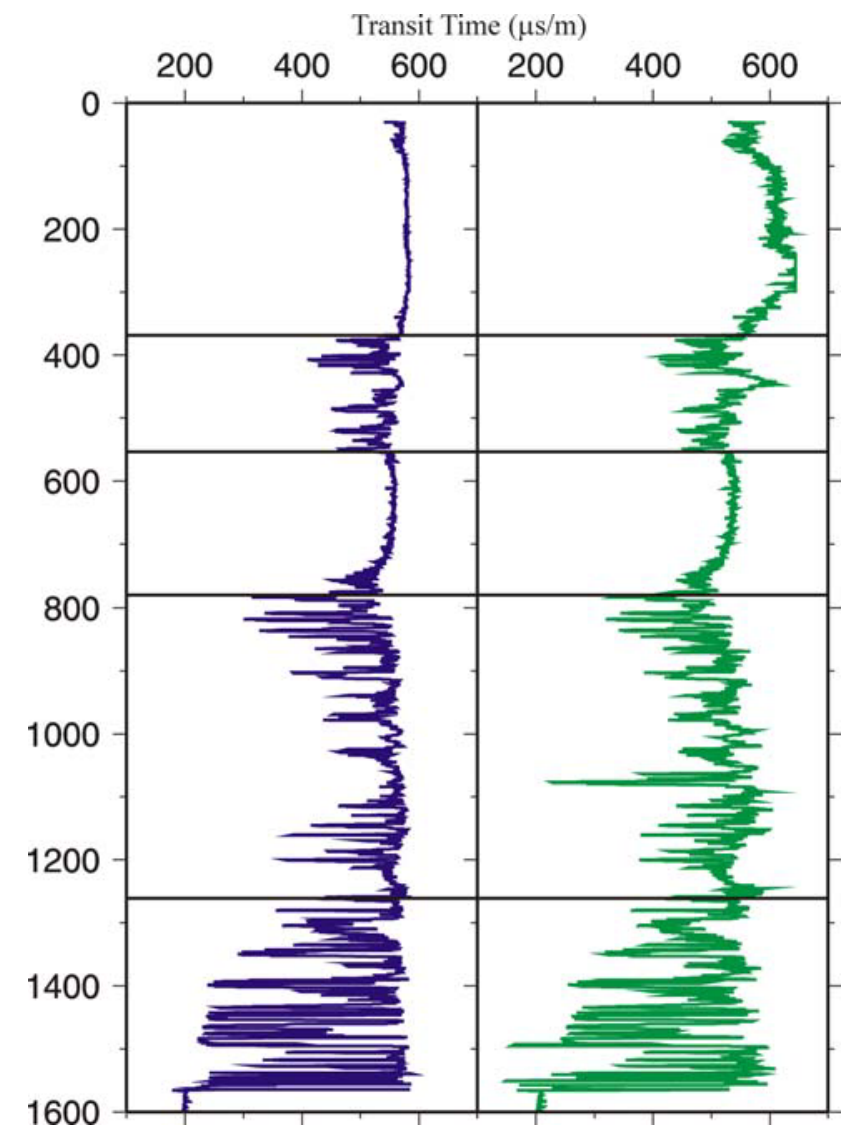

I.I.D. 2

Location:

Latitude: $33^{\circ} 12.2696^{\prime} \mathrm{N}$

Longitude: 11535.9075 ' W

Company: Imperial Thermal Products, Inc. \&

Schlumberger

Log Interval (feet):

Top: 100

Bottom: 5827

Date: December 1963

Feet Above Permanent Datum: 12 


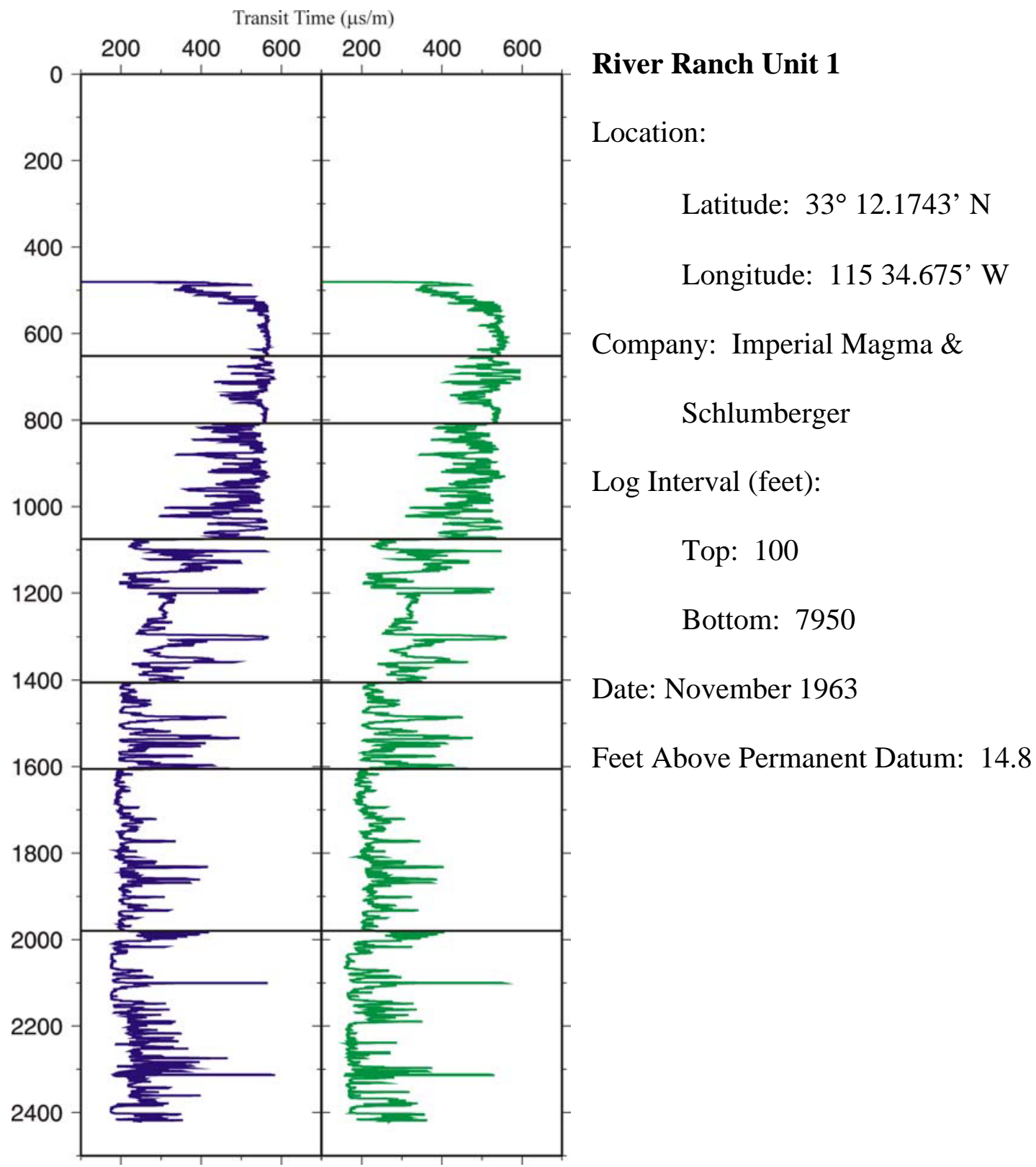




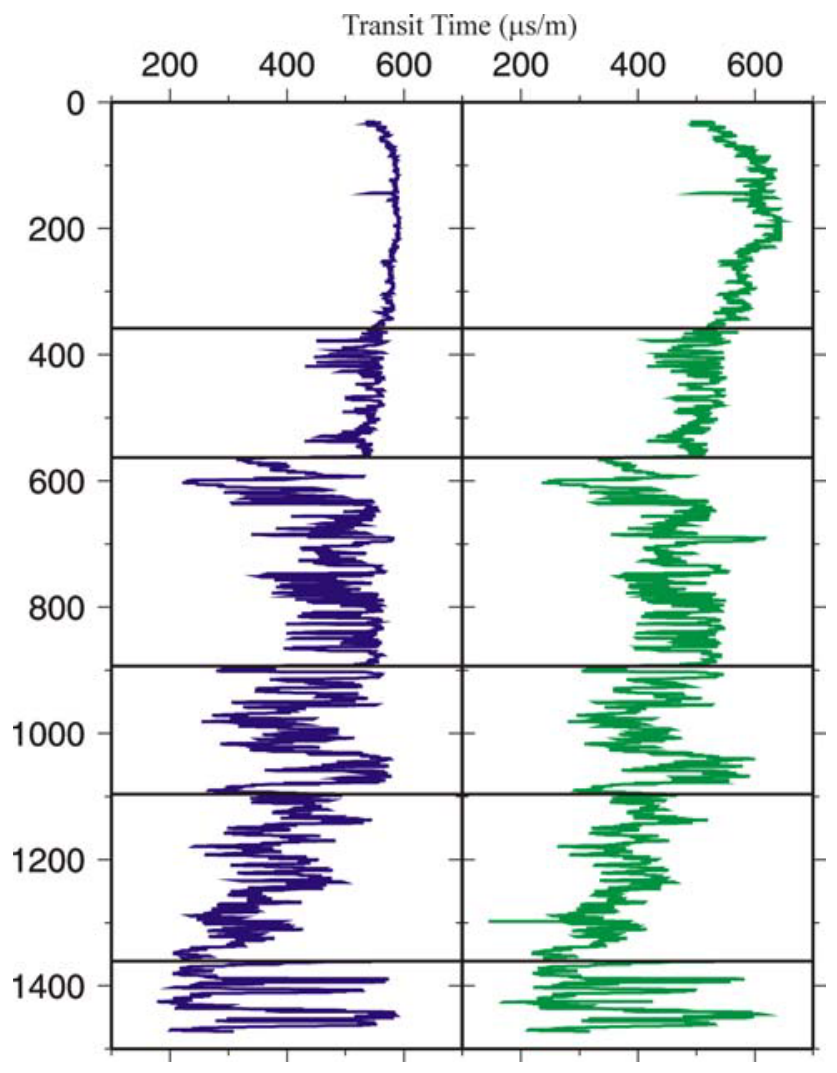

State of California 1

Location:

Latitude: $33^{\circ} 11.7949^{\prime} \mathrm{N}$

Longitude: 11535.625 ' W

Company: Imperial Thermal Products

Inc. \&

Schlumberger

Log Interval (feet):

Top: 102

Bottom: 4840

Date: May 1964

Feet Above Permanent Datum: 11 


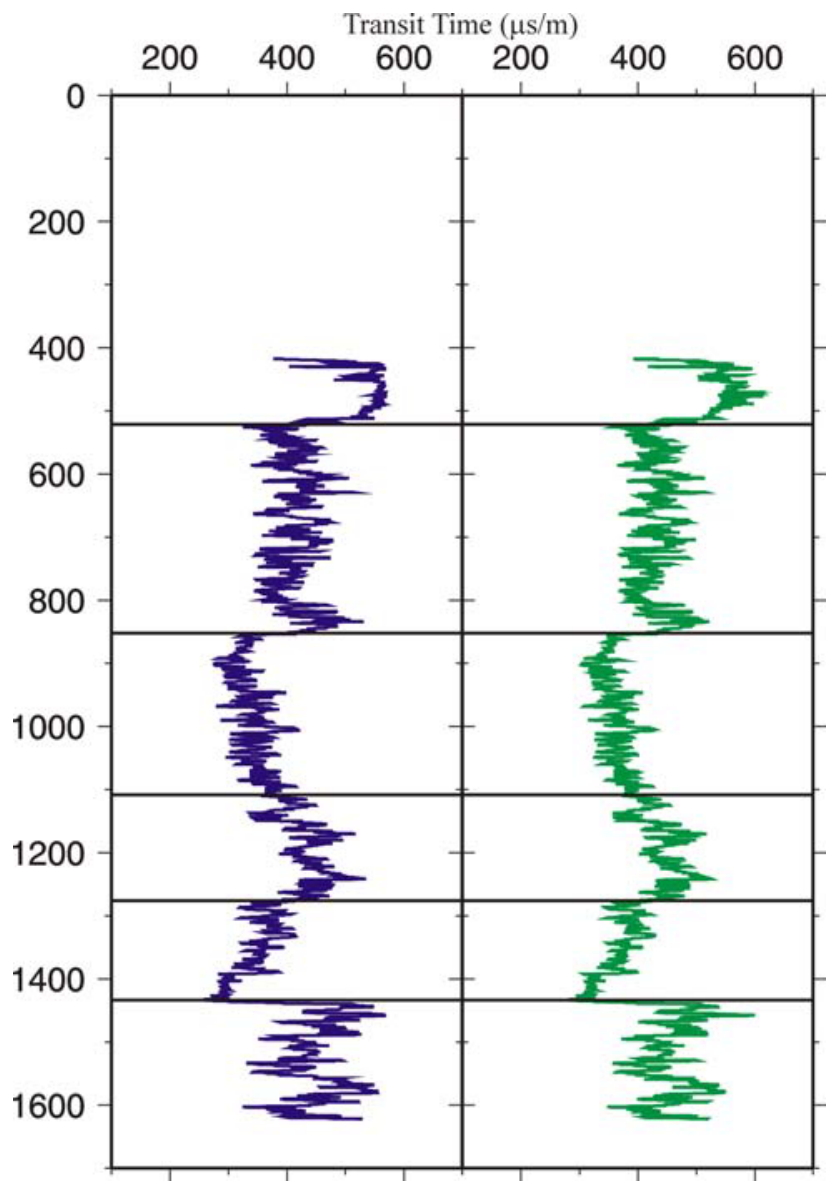

Sinclair 3

Location:

Latitude: $33^{\circ} 8.8323^{\prime} \mathrm{N}$

Longitude: $11536.7375^{\prime} \mathrm{W}$

Company: Geothermal Energy \&

Mineral

Corp. \& Schlumberger

Log Interval (feet):

Top: 1365

Bottom: 5330

Date: December 1962

Feet Above Permanent Datum: NA 


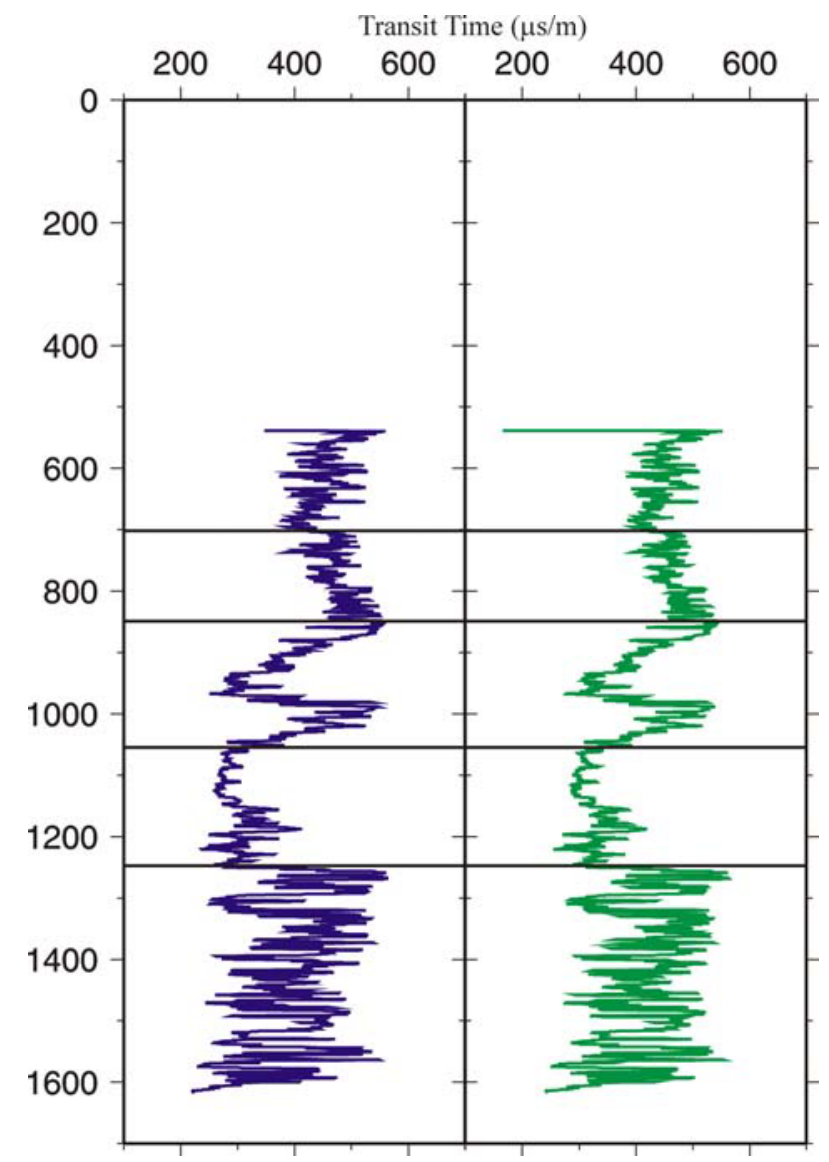

Sinclair 4

Location:

Latitude: $33^{\circ} 8.925^{\prime} \mathrm{N}$

Longitude: $115347.7875^{\prime} \mathrm{W}$

Company: Geothermal Energy \&

Mineral

Corp. \& Schlumberger

Log Interval (feet):

Top: 1768

Bottom: 5310

Date: May 1964

Feet Above Permanent Datum: NA 


\section{CURRICULUM VITAE}

Austin Holland was born on January 27, 1975 in Laramie, Wyoming. The first son of Paul Holland Jr. and Linda Holland, he graduated from Idaho Falls High School, Idaho Falls, Idaho in the spring of 1993. In his senior year of high school he was chosen to work for the school district writing computer programs and installing a computer network in a local school. He entered New Mexico Institute of Mining and Technology in the fall of 1993 with a Presidential Scholarship. In 1995 he transferred to the University of Idaho, Moscow, Idaho, where he received his bachelor's of science degree in geology in the spring of 1997. He worked for the Idaho National Engineering and Environmental Laboratory (INEEL) through a research fellowship in the summers of 1994,1995,1996, and during the summer of 1997 until the fall of 1998 . While at the INEEL he worked primarily with the seismic monitoring program and aided in the generation of the annual seismic reports. In the fall of 1998, he entered the Graduate School at The University of Texas at El Paso. He then took a full-time position with the seismic monitoring program at the INEEL in the spring of 1999.

Permanent address: 962 Eleventh St.

Idaho Falls, Idaho 83404

This thesis was typed by Austin Holland. 